\title{
Optimizing Social Security Benefits: Strategies For Married Couples With Above Average Age Differences And With Ratios Of Primary Insurance Amounts Of 0.5 Or Better
}

Fred Hebein, Ph.D., California State University - San Bernardino, USA

\begin{abstract}
The complex rules and inter-related choices regarding spousal and survivor benefits imbedded in the social security system make the optimization of lifetime benefits for married couples a complex decision which can reduce or increase lifetime benefits significantly-even hundreds of thousand dollars. This paper focuses on strategies for couples with above average age differences and with ratios of Primary Insurance Amount (PIA) of 0.5 or better. In regards to age differences, about $40 \%$ of marriages have 4 or more years in age difference between spouses. The difference of four or more years is important because it means that one spouse is at or past full retirement age (FRA) when the other spouse becomes 62. Since both spouses must be eligible for regular social security benefits (past 62 years of age) to jointly execute an optimization strategy, the time period to execute strategies for couples is reduced by above average age differences. This paper evaluates the financial benefits of three major strategies for couples with above average age differences and with PIA ratios of 0.5 or more: (1) Use "Restricted application" for spousal benefits; (2) Delay start of benefits until one spouse has reached 70 years of age; and; (3) Early start for benefits as soon as the youngest spouse reaches 62 years of age. Each strategy is affected by the differences of age between the individual spouses, their individual work records (PIA ratio), and their individual life expectancies. The analytical framework presented in this paper illustrates that couples can increase life time benefits by hundreds of thousands of dollars by choosing the appropriate strategy.
\end{abstract}

Keywords: Optimizing Social Security Benefits for Married Couples

\section{INTRODUCTION}

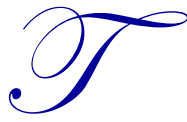

he complex rules and inter-related choices regarding spousal and survivor benefits imbedded in the social security system make the optimization of life-time benefits for married couples a rather intricate strategy selection decision. A number of books and articles are available to assist individuals in their choice of benefits and timing of start of benefits (Clements, 2009; Crawford and Lilien, 1981; Fahlund, 2009).

However, "Innumerable studies over the past decade have shown that many people lack the basic knowledge of the Social Security system necessary for making informed decisions about when to retire and claim benefits, a decision which will impact their savings and their overall financial security" (Rand Corp, 2010). Also, Kiplinger's Social Security Solutions states "Making the best possible selections related to your Social Security options can mean a material difference in the income it provides to you over the course of your retirement years." Kiplinger provides examples that show how a less than optimal choice may cost beneficiaries tens of thousands of dollars in forgone income. 
The selection of the correct strategy depends upon many factors such as the difference in ages of spouses (Johnson, 2002), the relative benefits of each spouse based upon their personal social security record (Muksian, 2011), the health of each spouse, the availability of suitable employment, the expected life span of each spouse (Henkens and Solinge, 2002), the cash needs of the couple, and other social network considerations such as children, grandchildren, etc. Clearly, optimization across so many variables is a complex evaluation.

As noted above, there are numerous studies and reference materials available to help couples make an informed decision. Many valuable resources are included in the bibliography attached to this paper. However, because of the large, perhaps infinite combinations of choices, to provide examples applicable to all situations is impossible.

In particular, examples of optimization tend to be sparse in which couples have above average age differences and retirement benefits within $50 \%$ of each other based upon their individual work records. One reason for the relative dearth of examples is that as the spousal age difference increases, fewer interactive strategies for optimization are available. For example, if a couple has more than 8 years of age difference, one spouse will be at 70 years of age before the other is eligible for social security benefits. There is no increase in benefits deferring past 70 years of age, and except for survivorship, care of minor children, and disability, there is little opportunity to take benefits before 62 years of age. Consequently, there are fewer examples of optimization strategies and references for couples with age differences of just 5 years or more.

\section{STRATEGY OPTIONS FOR COUPLES}

There are two basic strategies available for couples reaching retirement age: (1) "Claim and suspend" and (2) "Restricted application" (Nolo, 2012). "Claim and suspend" works for couples in which one spouse's dependent's benefits are less than $50 \%$ of the other spouse's full retirement benefits. In "claim or suspend" (or as it is often referred to as "file and suspend"), the worker "A", who is at full retirement age, files for benefits but suspends receipt of payments. The other spouse "B" can then file for spousal benefits on the record of spouse "A". The "claim and suspend" strategy will not work if spouse " $\mathrm{B}$ " is not yet 62 or if spouse " $\mathrm{B}$ " has retirement benefits on their own record of at least $50 \%$ of the benefits of the suspending spouse ("A").

The "claim and suspend" strategy is widely discussed in social security reference books and pamphlets. However, our analysis of strategies employs assumptions that make the "claim and suspend" strategy unrewarding. Because of the greater labor force participation of women, many baby boomer husbands and wives have significant individual work records Our assumptions that both spouses have retirement benefits, with the ratio of benefits (lower divided by higher) at 0.5 or greater, precludes the use of "claim and suspend" strategy. In addition, the length of time in which most interactive strategy options can be implemented becomes shorter as the average age difference grows. In fact, as noted earlier, with 8 years age difference or greater, and with each spouse having similar benefits (a ratio of 0.5 or greater), both the "claim and suspend" strategy and the "restricted application" strategy become unrewarding.

To use the strategy of "restricted application", at least one spouse must be at full retirement age and the average age difference must be less than 8 years. At full retirement age, either spouse can claim either full retirement or full dependent benefits. In "restricted application", the spouse who is less than FRA and who has the lower retirement benefits, decides to begin retirement (not spousal) benefits, which permits the spouse who is at full retirement age to receive dependent (spousal) benefits. In practice, it is usually the younger spouse who files for their social security retirement benefits, usually at 62 , and it is the older spouse who files for dependent benefits on the work record of the younger spouse. Because the older spouse did not start benefits on his own record, the older spouses continues to gain delayed retirement credits until the older spouse files for retirement benefits at 70 years of age.

At this point, some social security jargon must be introduced. The primary insurance amount (PIA) is the monthly income provided to the beneficiary at full retirement age (FRA). For individuals born between the years 1943-1954, the full retirement age is 66. (However, the FRA will increase gradually until 2027 when 67 years of age becomes FRA.) The PIA is calculated by formula from the Average Indexed Monthly Earnings (AIME), which 
is based upon the worker's highest earnings, selecting the best 35 years during the working life. The worker's earnings before age 60 are indexed to reflect the average increase in wage level in the U.S., making the earnings comparable over time.

The PIA formula for 2013 is: PIA $=(0.9 \mathrm{X}$ the first $\$ 791$ of AIME $)+(0.32$ of the next $\$ 3,977$ of AIME $)+$ ( $0.15 \mathrm{X}$ the remainder of AIME). Clearly, the formula favors lower income earners with the lower earnings most heavily weighted. Note that for every $\$ 1000$ in AIME above $\$ 4,768$, only $\$ 150$ is added to PIA. Once over the amount of $\$ 4,768$ additional income is weighted at $15 \%$. The low weighting at the higher income levels tends to diminish differences in benefits between higher income earners versus middle income earners. The PIA formula is adjusted every year. For more information, the reader can go to www.ssa.gov.

For the purposes of our analysis, the spouse with the lowest PIA is assumed to have a PIA equal to or greater than half of the primary insurance amount (PIA) of the spouse with the larger PIA. In other words, the ratio of the spouses' PIA's (lower PIA/ higher PIA) must be 0.5 or greater.

It should be noted that both strategies--- "claim and suspend" and "restricted application"---require at least one spouse to be of full retirement age (FRA) and the other spouse to be at least 62 years of age. In the "claim and suspend" strategy, the spouse at FRA claims and suspends retirement benefits. The younger spouse (at least 62 years of age) files for spousal benefits. Spousal benefits are paid at $50 \%$ of the claiming spouse's PIA. Also, when the spouse is age 62, the spousal benefit is reduced to $75 \%$ of the full spousal benefit because of early benefit reduction. Consequently, the spousal benefit, for couples with a 0.5 ratio or greater, becomes less than the retirement benefit available on the younger spouse's work record.

For example, Bill, 67 years of age, has a primary insurance amount (PIA) of \$2375/mo. His wife, Sandra, 62 , has a PIA of $\$ 1450 / \mathrm{mo}$. Sandra will have to take her retirement benefit of $0.75 \times \$ 1450=\$ 1087.50$, which is more than the amount available for dependent spousal benefits under Bill's record ( $0.5 \times 0.75 \times \$ 2375=\$ 890.63$.) In other words, there is no benefit to Bill filling and suspending benefits in order for Sandra to receive spousal benefits. Sandra will receive more from retirement benefits on her record than from claiming spousal benefits on Bill's record.

Note, that since Bill is 5 years older than his spouse, he could adopt the "restricted application" strategy and receive $50 \%$ of Sandra's \$1450/month (=\$725/month) until he claims retirement benefits with delayed retirement credits (DRC) at 70 years of age. (DRC increase benefits about 8\% per year. The maximum DRC for delaying start of benefits from FRA (66) until 70 years of age is 32\%). In Bill's case, the "restricted application" provides a monthly benefit of $\$ 1812.50(=\$ 1,087.50+\$ 725)$ and he gains DRC which will provide him a retirement benefit of $\$ 3,135$ at 70 years of age $(\$ 3,135=1.32 \times$ PIA $=1.32 \times \$ 2375)$.

However, if Bill were 8 years older than his spouse, he would have to claim his retirement benefits of $\$ 3135 /$ month (= \$2375/month x 1.32 given delayed retirement credits (DRC) of 32\%). Sandra would have the choice of filing for retirement benefits or waiting. Her retirement benefit remains at $\$ 1087.50 / \mathrm{month}$ if she files at 62 and her spousal benefit remains at $\$ 890.63$ despite Bill's increased retirement benefit from delayed retirement credits. The spousal benefit is based upon the other spouse's PIA only and does not include DRC. However, when Bill dies, Sandra, if she is at full retirement age, will receive $100 \%$ of Bill's retirement benefits of $\$ 3135 /$ month. Survivor's benefits include DRC.

As the previous example illustrates, an important consideration for couples is the survivor benefit (O'Rand and Parkas, 2002; Fisher, 2007; Burtless, 1986) which includes delayed retirement credits (DRC). The widow, at FRA, will receive $100 \%$ of the deceased spouse's retirement benefits including the DRC (Landis, 2012). Another important issue to consider is the couple's cash requirements. If the couple can utilize the "restricted application", the couple can receive retirement and spousal benefits, usually on the younger spouse's work record. The "restricted application" permits the other spouse to build their monthly benefit by DRC until 70 years of age. If the couple has a high ratio of retirement benefits, the "claim and suspend" strategy provides less income than the "restricted application" strategy. As noted above, many wives and husbands today have similar retirement benefits (ratio above 0.5 ). For couples with a 0.5 ratio or greater, the "claim and suspend" strategy is relatively unrewarding and the "restricted application" strategy is comparatively superior. 


\section{FOCUS OF PAPER}

This paper focuses on strategies for couples whose retirement benefits have a ratio of 0.5 or better (lower PIA/higher PIA) and who have an above average age differences between spouses. First, consider age differences. Looking at Table 1 reveals that about $40 \%$ of marriages have 4 or more years in age difference between spouses. Furthermore, about $31.2 \%$ of marriages have 5 or more years in age difference between spouses. The example strategies provided in most social security references assume a smaller age difference. The difference of four or more years is important because it means that one spouse is at or past full retirement age (FRA) when the other spouse becomes 62. Since most optimizing strategies require both spouses to be eligible for regular social security benefits (past 62 years of age), and at least one spouse to be at FRA, the time period to execute strategies for optimization for interactive couples' benefits is reduced by age differences beyond 4 years.

Table 1

Married Couples By Differences In Ages Between Husband And Wife: 1999

\begin{tabular}{|c|c|c|}
\hline Age Differences & All Married Couples (000's) & Percent Distribution \\
\hline Total & 55,849 & 100.0 \\
\hline Husband 20 or more years older than wife & 447 & 0.8 \\
\hline Husband 15 to 19 years older than wife & 830 & 1.5 \\
\hline Husband 10 to 14 years older than wife & 2,735 & 4.9 \\
\hline Husband 6 to 9 years older than wife & 6,891 & 12.3 \\
\hline Husband 4 to 5 years older than wife & 7,687 & 13.8 \\
\hline Husband 2 to 3 years older than wife & 12,321 & 22.1 \\
\hline Husband and wife within one year & 18,096 & 32.4 \\
\hline Wife 2 to 3 years older than husband & 3,320 & 5.9 \\
\hline Wife 4 to 5 years older than husband & 1,622 & 2.9 \\
\hline Wife 6 to 9 years older than husband & 1,222 & 2.2 \\
\hline Wife 10 to 14 years older than husband & 480 & 0.9 \\
\hline Wife 15 to 19 years older than husband & 112 & 0.2 \\
\hline Wife 20 or more years older than husband & 87 & 0.2 \\
\hline
\end{tabular}

US Census Bureau, Based upon Current Population Survey

http://www.census.gov/population/www/

In the calculated tables to follow, the lower income spouse has a PIA of $\$ 1478$ based upon a work record of 20 years of "substantial earnings". Social security provides a table which shows the amount of dollars needed in every year since 1937 to qualify for "substantial earnings". "Substantial earnings" are important in the calculation of the WEP (Windfall Elimination Provision). The WEP was instituted to reduce the benefits of double dipping by pensioners. For more information, the reader is referred to SSA Publication No. 05-10045, January 2012, ICN 460275. In our calculated tables, the lower income spouse has a small pension of $\$ 444 /$ month based upon working as a teacher in a school system which did not participate in social security. The WEP extracts a penalty of 50\% (\$222/month) of the teacher's pension from the social security benefit. Although the WEP adjustment is not very large, it is included to provide an illustration of the WEP consideration in social security optimization strategies (Blankenship, 2011).

\section{STRATEGIES AND ASSUMPTIONS}

This paper evaluates the financial benefits of three major strategies for couples with above average age differences and with spouses having PIA's equal or greater than 0.5 ratio based upon their individual AIME on their work records. The strategies are: (1) Use "Restricted application" for spousal benefits; (2) Delay start of benefits until one spouse has reached 70 years of age; and; (3) Early start for benefits as soon as the youngest spouse reaches 62 years of age. For strategies 2 and 3, it is assumed that both spouses will begin benefits on their own work record at the same time. By beginning benefits at the same time, spouses can start benefits when both spouses are believed to have finished working. 
At this point, let us review the age difference assumption underlying the calculations for the tables to follow in this paper. For the purpose of this paper, an age difference of five (5) years is assumed. The husband or wife may be the older spouse. The choice of five years reflects several considerations. First, the percentage of marriages with age difference between zero and nine years is $91.5 \%$. Since the interval includes all of the ninth year until the beginning of the tenth year, five years is in the middle of the range. Second, if we make the assumption that the age differences are normally distributed and interpolate the interval for 4 to 5 years on Table 1, the total area between +5 and -5 (wife older) is about .688 , which implies that the a standard deviation of 1.0 occurs at about 5 years. Also, and important for the decision making analysis necessary for optimization of social security benefits, the five year period requires decisions to be made by the couples considering that when one spouse is past FRA, the younger spouse may not yet be 62 .

\section{DESCRIPTION OF STRATEGIES}

We explore three main strategies in this analysis. Strategy 1 uses the "restricted application". In strategy 1, the individual (spouse "B"), who is assumed to have the lowest primary insurance amount (PIA) on their own record, begins benefits at 62. The other spouse "A" (at or past FRA) makes a "restricted application" for spousal benefits which permits " $A$ " to gain monthly benefits immediately on "B"'s record, but allows " $A$ " to receive delayed retirement credits (DRC). DRC add about $8 \%$ per year to monthly benefits. In strategy 1, both "A" and "B" receive benefits on "B"s record until "A" reaches 70 years of age and begins receipt of monthly benefits at the higher DRC rate. "B" continues to receive benefits at the earlier established amount. Strategy 1 works best for couples where "B" has become unemployed with few prospects for future full time employment, has little likelihood of exceeding the $\$ 14,640$ earnings limit (2012), but who has substantial social security benefits on their own record.

In strategy 2, individual "A", who is the oldest, delays until 70 years of age to start benefits at the higher DRC rate (waiting until 70 years of age increases monthly benefits to about $132 \%$ of PIA at FRA). The youngest spouse "B" waits until near full retirement age. By this strategy, the youngest spouse can receive near $100 \%$ of their PIA at FRA. It is generally not rewarding for "B" to wait until 70 years of age to collect DRC. The younger spouse is more likely to collect survivor benefits which are $100 \%$ of the older spouse's benefits including the DRC. Strategy 2 is best for couples in which both spouses are still employed, have long life expectancies, and who have sufficient funds to postpone early receipt of social security benefits.

In strategy 3, both individuals begin benefits on their own record when the youngest spouse "B" can start benefits. The assumption here is that the highest wage earner can work until both spouses are eligible for social security benefits. When the youngest spouse reaches 62 , the older spouse retires at 67 (given the 5 year age difference.) This strategy permits some increased individual and survivor benefits from DRC and early access to benefits for the younger spouse. Strategy 3 maximizes life time income for couples who have above average age differences, who have qualified for social security on their own records, who have below average life expectancies, and who can afford to live on their combined social security benefits.

\section{BASIC ASSUMPTIONS UNDERLYING THE COMPUTATIONAL TABLES}

To analysis the three strategies, Tables 2 through 13 show the computation of annual benefits and their accumulation over the expected live span of the couple. Four different life spans of spouse "A" are used: 75 years, 80 years, 85 years, and 90 years. Spouse "B" is expected to live to 90 . (Based upon current mortality tables, there is a strong likelihood of at least one spouse living to 90 years of age.) Benefits are assumed paid until the last day of the terminal year. The average age difference is assumed to be 5 years, with " $\mathrm{A}$ " being the older spouse.

The PIA's for A and B are \$2371/month and \$1478/month respectively. The PIA's are based on 35 years AIME for "A" and an AIME with 20 years of "substantial earnings" for "B". It is assumed that "B" had 5 years working for a government agency in which no social security taxes were paid and a small independent pension of $\$ 444$ was gained. The Windfall Elimination Provision reduces "B"s retirement benefit by $50 \%$ or $\$ 222$. No adjustment for inflation is provided because social security benefits are adjusted for inflation (Duggar and Gillingham, 1999; Hobjin and Lagakos, 2003). It has been the goal of Congress to maintain the "real" benefits of social security by cost of living adjustments (COLA). 
To simplify the computations, each spouse will gain benefits throughout the whole year of that age and that the years are consistent between spouses. That is, referring to strategy 1, Table 2, when spouse "A" receives an annual benefit of $\$ 7536$ at age 67 , the spouse "B" at age 62 , also receives an annual benefit of $\$ 11,304$ the same year.

For strategy 1, spouse "A" receives $50 \%$ of spouse "B"s retirement benefit. The $50 \%$ amount is based upon the social security rule for spousal benefit at full retirement age. If spouse " $\mathrm{A}$ " was less than FRA, the benefit would be reduced. Because Spouse "B" is only 62, the retirement benefit is reduced to $75 \%$ of the net retirement benefit after reduction by WEP. The annual benefit for " $\mathrm{A}$ " is $\$ 7536(=12 \times 0.5 \times \$(1478-222))$. The annual benefit for " $\mathrm{B}$ " is $\$ 11,304(=12 \mathrm{X}(1478-222) \mathrm{X} 0.75)$. When spouse " $\mathrm{A}$ " turns 70 years of age, the annual benefit increases to $\$ 37,557(=12 \times 1.32 \times 2371)$.

For strategy 2, spouse "A" does not take benefits until 70 years of age. Spouse "B" waits until 65 to begin benefits. Spouse "A" has annual benefits at 70 of $\$ 37,557(=12$ X 1.32 X 2371). Spouse "B" has annual benefits of $\$ 14,067$ (= 12 X $0.9333 \times 1256$ ). The factor 0.9333 reflects " $B$ "s retirement benefit reduction because " $B$ " is 65 , or one year less than full retirement age. Strategy 2 evaluates whether a couple meeting our assumptions of age and PIA ratio should delay taking social security benefits.

For strategy 3, spouse " $\mathrm{A}$ " begins their retirement benefits when the younger spouse "B" can begin taking their retirement benefits. Spouse "A" has annual benefits of $\$ 30,728(=12 \times 1.08 \times 2371)$. The factor 1.08 reflects the DRC gained by delaying beginning benefits by one year. The annual benefits for " $\mathrm{B}$ " are $\$ 11,304$ (= $12 \mathrm{X}$ (1478-222) X 0.75). Strategy 3 evaluates whether a couple meeting our assumptions of age and PIA ratio should begin social security benefits as soon as the younger spouse is eligible.

\section{ANALYSIS OF CALCULATED TABLES FOR STRATEGY 1}

Strategy 1 uses the "restricted application" strategy. To briefly describe, at least one spouse ("A") must be at FRA. The younger partner (spouse "B") begins retirement benefits at 62. Spouse "A" makes a "restricted claim" for dependent spousal benefits which permits "A" to gain monthly income immediately on "B"'s record, but allows "A" to gain delayed retirement credits (DRC).

A primary advantage of strategy 1 is that it permits spouse " $\mathrm{A}$ " to maximize retirement benefits using delayed retirement credits (DRC). These enhanced benefits will provide increased income to spouse " $A$ " and then pass to the other spouse when spouse "A" dies. Another advantage is that the couple begins receiving some benefits from social security immediately reducing the opportunity cost of delayed retirement benefits for spouse "A".

The strategy 1 works best for couples in which the younger spouse is unlikely to find full time employment again, is unlikely to have earnings which exceed the $\$ 14,640$ limit, has a lower PIA than the older spouse, and has a long life expectancy. If the survivor is at FRA, the survivor benefit is $100 \%$ of the deceased spouse's full retirement benefit which includes DRC. In other words, for husbands and wives with above average age differences, the older spouse's enhanced retirement benefits are received by the younger spouse for their entire remaining life. For optimization from the couple's perspective, the couple receives the enhanced retirement benefit for spouse "A"s life and subsequently, for spouse "B"s remaining life. Given that most mortality estimates for couples suggest that at least one will live to 90 years of age, the enhanced retirement benefit from DRC persists until the death of both spouses.

An important caveat: the underlying assumption for strategy 1 is that the older spouse also has the higher PIA. If the younger spouse has the higher PIA, other strategies should be explored. However, the examples used in this paper are meant to be representative of the majority of couples who have an above average age difference and a PIA ratio (lower PIA/higher PIA) equal to or greater than 0.5. In many couples, the older spouse, usually the husband, has the larger PIA and the lower life expectancy. 
Looking at Table 2, Strategy 1 for 75/90, spouse "A", age 67, and spouse "B", age 62, receive benefits of $\$ 7,536$ and $\$ 11,304$ respectively for a total annual benefit of $\$ 18,840$. When spouse " $A$ " reaches 70 years of age, the annual benefit rises to $\$ 37,557$ (given the DRC) for a total combined benefit for the couple of $\$ 48,861$. The higher total benefit continues until " $\mathrm{A}$ " dies and spouse "B" begins receiving survivor benefits of $\$ 37,557$ at 71 years of age. The annual benefit of $\$ 37,557$ continues until " $B$ " dies after 90 years. The cumulative benefits for the couple are $\$ 349,684$ at the end of age 75 for spouse "A" and are $\$ 1,100,817$ for the couple at the end of age 90 for spouse "B".

Table 2 - Strategy 1 75/90 - Restricted Application

B" Begins Retirement Benefits and "A" Begins Spousal Benefits on "B"s Record

\begin{tabular}{|c|c|c|c|c|c|}
\hline \multicolumn{2}{|c|}{ Age } & \multicolumn{4}{|c|}{ Benefits } \\
\hline Spouse A & Spouse B & Annual A & Annual B & Total & Cumulative \\
\hline 67 & 62 & $\$ 7,536$ & $\$ 11,304$ & $\$ 18,840$ & $\$ 18,840$ \\
\hline 68 & 63 & $\$ 7,536$ & $\$ 11,304$ & $\$ 18,840$ & $\$ 37,680$ \\
\hline 69 & 64 & $\$ 7,536$ & $\$ 11,304$ & $\$ 18,840$ & $\$ 56,520$ \\
\hline 70 & 65 & $\$ 37,557$ & $\$ 11,304$ & $\$ 48,861$ & $\$ 105,381$ \\
\hline 71 & 66 & $\$ 37,557$ & $\$ 11,304$ & $\$ 48,861$ & $\$ 154,241$ \\
\hline 72 & 67 & $\$ 37,557$ & $\$ 11,304$ & $\$ 48,861$ & $\$ 203,102$ \\
\hline 73 & 68 & $\$ 37,557$ & $\$ 11,304$ & $\$ 48,861$ & $\$ 251,963$ \\
\hline 74 & 69 & $\$ 37,557$ & $\$ 11,304$ & $\$ 48,861$ & $\$ 300,823$ \\
\hline 75 & 70 & $\$ 37,557$ & $\$ 11,304$ & $\$ 48,861$ & $\$ 349,684$ \\
\hline 76 & 71 & $\$ 0$ & $\$ 37,557$ & $\$ 37,557$ & $\$ 387,240$ \\
\hline 77 & 72 & $\$ 0$ & $\$ 37,557$ & $\$ 37,557$ & $\$ 424,797$ \\
\hline 78 & 73 & $\$ 0$ & $\$ 37,557$ & $\$ 37,557$ & $\$ 462,354$ \\
\hline 79 & 74 & $\$ 0$ & $\$ 37,557$ & $\$ 37,557$ & $\$ 499,910$ \\
\hline 80 & 75 & $\$ 0$ & $\$ 37,557$ & $\$ 37,557$ & $\$ 537,467$ \\
\hline 81 & 76 & $\$ 0$ & $\$ 37,557$ & $\$ 37,557$ & $\$ 575,024$ \\
\hline 82 & 77 & $\$ 0$ & $\$ 37,557$ & $\$ 37,557$ & $\$ 612,580$ \\
\hline 83 & 78 & $\$ 0$ & $\$ 37,557$ & $\$ 37,557$ & $\$ 650,137$ \\
\hline 84 & 79 & $\$ 0$ & $\$ 37,557$ & $\$ 37,557$ & $\$ 687,694$ \\
\hline 85 & 80 & $\$ 0$ & $\$ 37,557$ & $\$ 37,557$ & $\$ 725,250$ \\
\hline 86 & 81 & $\$ 0$ & $\$ 37,557$ & $\$ 37,557$ & $\$ 762,807$ \\
\hline 87 & 82 & $\$ 0$ & $\$ 37,557$ & $\$ 37,557$ & $\$ 800,364$ \\
\hline 88 & 83 & $\$ 0$ & $\$ 37,557$ & $\$ 37,557$ & $\$ 837,920$ \\
\hline 89 & 84 & $\$ 0$ & $\$ 37,557$ & $\$ 37,557$ & $\$ 875,477$ \\
\hline 90 & 85 & $\$ 0$ & $\$ 37,557$ & $\$ 37,557$ & $\$ 913,033$ \\
\hline 91 & 86 & $\$ 0$ & $\$ 37,557$ & $\$ 37,557$ & $\$ 950,590$ \\
\hline 92 & 87 & $\$ 0$ & $\$ 37,557$ & $\$ 37,557$ & $\$ 988,147$ \\
\hline 93 & 88 & $\$ 0$ & $\$ 37,557$ & $\$ 37,557$ & $\$ 1,025,703$ \\
\hline 94 & 89 & $\$ 0$ & $\$ 37,557$ & $\$ 37,557$ & $\$ 1,063,260$ \\
\hline 95 & 90 & $\$ 0$ & $\$ 37,557$ & $\$ 37,557$ & $\$ 1,100,817$ \\
\hline
\end{tabular}

Table assumes PIA of $\$ 2,371(\mathrm{~A})$ and PIA of $\$ 1,478(\mathrm{~B})$. DRC $=1.32$. WEP (B) $=\$ 222$. "B" starts at 62 which reduces benefits to 0.75 of PIA(B). Age of death is 75 (spouse A) and 90 (spouse B).

Tables 3, 4, and 5 illustrate strategy 1 for the spousal ages of 80/90, 85/90 and 90/90, As in Table 2, spouse "A", age 67, and spouse "B", age 62 , receive benefits of $\$ 7,536$ and $\$ 11,304$ respectively for a total annual benefit of $\$ 18,840$. When spouse "A" reaches 70 years of age, the annual benefit rises to $\$ 37,557$ (given the DRC) for a total combined benefit for the couple of $\$ 48,861$. The higher total benefit continues until "A" dies and spouse "B" begins receiving survivor benefits of $\$ 37,557$. The annual benefits of $\$ 37,557$ continue until "B" dies after 90 years.

The cumulative benefits for the couple who survives to $80 / 90$ (Table 3) are $\$ 593,987$ at the end of age 80 for spouse "A" and are $\$ 1,157,337$ for the couple at the end of age 90 for spouse "B". The cumulative benefits for the couple who survives to $85 / 90$ (Table 4 ) are $\$ 838,290$ at the end of age 85 for spouse "A" and are $\$ 1,213,857$ for the couple at the end of age 90 for spouse "B". The cumulative benefits for the couple who survives to 90/90 (Table 5) are $\$ 1,082,593$ at the end of age 90 for spouse " $A$ " and are $\$ 1,270,377$ for the couple at the end of age 90 for spouse "B". 
Table 3 - Strategy 1 80/90 - Restricted Application

B" Begins Retirement Benefits and "A" Begins Spousal Benefits on "B"s Record

\begin{tabular}{|c|c|c|c|c|c|}
\hline \multicolumn{2}{|c|}{ Age } & \multicolumn{4}{|c|}{ Benefits } \\
\hline Spouse A & Spouse B & Annual A & Annual B & Total & Cumulative \\
\hline 67 & 62 & $\$ 7,536$ & $\$ 11,304$ & $\$ 18,840$ & $\$ 18,840$ \\
\hline 68 & 63 & $\$ 7,536$ & $\$ 11,304$ & $\$ 18,840$ & $\$ 37,680$ \\
\hline 69 & 64 & $\$ 7,536$ & $\$ 11,304$ & $\$ 18,840$ & $\$ 56,520$ \\
\hline 70 & 65 & $\$ 37,557$ & $\$ 11,304$ & $\$ 48,861$ & $\$ 105,381$ \\
\hline 71 & 66 & $\$ 37,557$ & $\$ 11,304$ & $\$ 48,861$ & $\$ 154,241$ \\
\hline 72 & 67 & $\$ 37,557$ & $\$ 11,304$ & $\$ 48,861$ & $\$ 203,102$ \\
\hline 73 & 68 & $\$ 37,557$ & $\$ 11,304$ & $\$ 48,861$ & $\$ 251,963$ \\
\hline 74 & 69 & $\$ 37,557$ & $\$ 11,304$ & $\$ 48,861$ & $\$ 300,823$ \\
\hline 75 & 70 & $\$ 37,557$ & $\$ 11,304$ & $\$ 48,861$ & $\$ 349,684$ \\
\hline 76 & 71 & $\$ 37,557$ & $\$ 11,304$ & $\$ 48,861$ & $\$ 398,544$ \\
\hline 77 & 72 & $\$ 37,557$ & $\$ 11,304$ & $\$ 48,861$ & $\$ 447,405$ \\
\hline 78 & 73 & $\$ 37,557$ & $\$ 11,304$ & $\$ 48,861$ & $\$ 496,266$ \\
\hline 79 & 74 & $\$ 37,557$ & $\$ 11,304$ & $\$ 48,861$ & $\$ 545,126$ \\
\hline 80 & 75 & $\$ 37,557$ & $\$ 11,304$ & $\$ 48,861$ & $\$ 593,987$ \\
\hline 81 & 76 & $\$ 0$ & $\$ 37,557$ & $\$ 37,557$ & $\$ 631,544$ \\
\hline 82 & 77 & $\$ 0$ & $\$ 37,557$ & $\$ 37,557$ & $\$ 669,100$ \\
\hline 83 & 78 & $\$ 0$ & $\$ 37,557$ & $\$ 37,557$ & $\$ 706,657$ \\
\hline 84 & 79 & $\$ 0$ & $\$ 37,557$ & $\$ 37,557$ & $\$ 744,214$ \\
\hline 85 & 80 & $\$ 0$ & $\$ 37,557$ & $\$ 37,557$ & $\$ 781,770$ \\
\hline 86 & 81 & $\$ 0$ & $\$ 37,557$ & $\$ 37,557$ & $\$ 819,327$ \\
\hline 87 & 82 & $\$ 0$ & $\$ 37,557$ & $\$ 37,557$ & $\$ 856,884$ \\
\hline 88 & 83 & $\$ 0$ & $\$ 37,557$ & $\$ 37,557$ & $\$ 894,440$ \\
\hline 89 & 84 & $\$ 0$ & $\$ 37,557$ & $\$ 37,557$ & $\$ 931,997$ \\
\hline 90 & 85 & $\$ 0$ & $\$ 37,557$ & $\$ 37,557$ & $\$ 969,553$ \\
\hline 91 & 86 & $\$ 0$ & $\$ 37,557$ & $\$ 37,557$ & $\$ 1,007,110$ \\
\hline 92 & 87 & $\$ 0$ & $\$ 37,557$ & $\$ 37,557$ & $\$ 1,044,667$ \\
\hline 93 & 88 & $\$ 0$ & $\$ 37,557$ & $\$ 37,557$ & $\$ 1,082,223$ \\
\hline 94 & 89 & $\$ 0$ & $\$ 37,557$ & $\$ 37,557$ & $\$ 1,119,780$ \\
\hline 95 & 90 & $\$ 0$ & $\$ 37,557$ & $\$ 37,557$ & $\$ 1,157,337$ \\
\hline
\end{tabular}

Table assumes PIA of $\$ 2,371(\mathrm{~A})$ and PIA of $\$ 1,478(\mathrm{~B})$. DRC $=1.32$. WEP (B) $=\$ 222$. "B" starts at 62 which reduces benefits to 0.75 of PIA(B). Age of death is 80 (spouse A) and 90 (spouse B).

Table 4 - Strategy $185 / 90$ - Restricted Application

B" Begins Retirement Benefits and "A" Begins Spousal Benefits on "B"s Record

\begin{tabular}{|c|c|c|c|c|c|}
\hline \multicolumn{2}{|c|}{ Age } & \multicolumn{4}{|c|}{ Benefits } \\
\hline Spouse A & Spouse B & Annual A & Annual B & Total & Cumulative \\
\hline 67 & 62 & $\$ 7,536$ & $\$ 11,304$ & $\$ 18,840$ & $\$ 18,840$ \\
\hline 68 & 63 & $\$ 7,536$ & $\$ 11,304$ & $\$ 18,840$ & $\$ 37,680$ \\
\hline 69 & 64 & $\$ 7,536$ & $\$ 11,304$ & $\$ 18,840$ & $\$ 56,520$ \\
\hline 70 & 65 & $\$ 37,557$ & $\$ 11,304$ & $\$ 48,861$ & $\$ 105,381$ \\
\hline 71 & 66 & $\$ 37,557$ & $\$ 11,304$ & $\$ 48,861$ & $\$ 154,241$ \\
\hline 72 & 67 & $\$ 37,557$ & $\$ 11,304$ & $\$ 48,861$ & $\$ 203,102$ \\
\hline 73 & 68 & $\$ 37,557$ & $\$ 11,304$ & $\$ 48,861$ & $\$ 251,963$ \\
\hline 74 & 69 & $\$ 37,557$ & $\$ 11,304$ & $\$ 48,861$ & $\$ 300,823$ \\
\hline 75 & 70 & $\$ 37,557$ & $\$ 11,304$ & $\$ 48,861$ & $\$ 349,684$ \\
\hline 76 & 71 & $\$ 37,557$ & $\$ 11,304$ & $\$ 48,861$ & $\$ 398,544$ \\
\hline 77 & 72 & $\$ 37,557$ & $\$ 11,304$ & $\$ 48,861$ & $\$ 447,405$ \\
\hline 78 & 73 & $\$ 37,557$ & $\$ 11,304$ & $\$ 48,861$ & $\$ 496,266$ \\
\hline 79 & 74 & $\$ 37,557$ & $\$ 11,304$ & $\$ 48,861$ & $\$ 545,126$ \\
\hline 80 & 75 & $\$ 37,557$ & $\$ 11,304$ & $\$ 48,861$ & $\$ 593,987$ \\
\hline 81 & 76 & $\$ 37,557$ & $\$ 11,304$ & $\$ 48,861$ & $\$ 642,848$ \\
\hline 82 & 77 & $\$ 37,557$ & $\$ 11,304$ & $\$ 48,861$ & $\$ 691,708$ \\
\hline 83 & 78 & $\$ 37,557$ & $\$ 11,304$ & $\$ 48,861$ & $\$ 740,569$ \\
\hline 84 & 79 & $\$ 37,557$ & $\$ 11,304$ & $\$ 48,861$ & $\$ 789,430$ \\
\hline 85 & 80 & $\$ 37,557$ & $\$ 11,304$ & $\$ 48,861$ & $\$ 838,290$ \\
\hline 86 & 81 & $\$ 0$ & $\$ 37,557$ & $\$ 37,557$ & $\$ 875,847$ \\
\hline 87 & 82 & $\$ 0$ & $\$ 37,557$ & $\$ 37,557$ & $\$ 913,404$ \\
\hline 88 & 83 & $\$ 0$ & $\$ 37,557$ & $\$ 37,557$ & $\$ 950,960$ \\
\hline 89 & 84 & $\$ 0$ & $\$ 37,557$ & $\$ 37,557$ & $\$ 988,517$ \\
\hline 90 & 85 & $\$ 0$ & $\$ 37,557$ & $\$ 37,557$ & $\$ 1,026,073$ \\
\hline
\end{tabular}




\begin{tabular}{|c|c|c|c|c|c|}
\hline 91 & 86 & $\$ 0$ & $\$ 37,557$ & $\$ 37,557$ & $\$ 1,063,630$ \\
\hline 92 & 87 & $\$ 0$ & $\$ 37,557$ & $\$ 37,557$ \\
\hline 93 & 88 & $\$ 0$ & $\$ 37,557$ & $\$ 37,557$ \\
\hline 94 & 89 & $\$ 0$ & $\$ 37,557$ & $\$ 1,138,743$ & $\$ 1,187$ \\
\hline 95 & 90 & $\$ 0$ & $\$ 37,557$ & $\$ 37,557$ & $\$ 1,500$ \\
\hline
\end{tabular}

Table assumes PIA of $\$ 2,371(\mathrm{~A})$ and PIA of $\$ 1,478(\mathrm{~B})$. DRC $=1.32$. WEP $(\mathrm{B})=\$ 222$. "B" starts at 62 which reduces benefits to 0.75 of PIA(B). Age of death is 85 (spouse A) and 90 (spouse B).

Table 5 - Strategy 1 90/90 - Restricted Application

B" Begins Retirement Benefits and "A" Begins Spousal Benefits on "B"s Record

\begin{tabular}{|c|c|c|c|c|c|}
\hline \multicolumn{2}{|c|}{ Age } & \multicolumn{4}{|c|}{ Benefits } \\
\hline Spouse A & Spouse B & Annual A & Annual B & Total & Cumulative \\
\hline 66 & 61 & & & & \\
\hline 67 & 62 & $\$ 7,536$ & $\$ 11,304$ & $\$ 18,840$ & $\$ 18,840$ \\
\hline 68 & 63 & $\$ 7,536$ & $\$ 11,304$ & $\$ 18,840$ & $\$ 37,680$ \\
\hline 69 & 64 & $\$ 7,536$ & $\$ 11,304$ & $\$ 18,840$ & $\$ 56,520$ \\
\hline 70 & 65 & $\$ 37,557$ & $\$ 11,304$ & $\$ 48,861$ & $\$ 105,381$ \\
\hline 71 & 66 & $\$ 37,557$ & $\$ 11,304$ & $\$ 48,861$ & $\$ 154,241$ \\
\hline 72 & 67 & $\$ 37,557$ & $\$ 11,304$ & $\$ 48,861$ & $\$ 203,102$ \\
\hline 73 & 68 & $\$ 37,557$ & $\$ 11,304$ & $\$ 48,861$ & $\$ 251,963$ \\
\hline 74 & 69 & $\$ 37,557$ & $\$ 11,304$ & $\$ 48,861$ & $\$ 300,823$ \\
\hline 75 & 70 & $\$ 37,557$ & $\$ 11,304$ & $\$ 48,861$ & $\$ 349,684$ \\
\hline 76 & 71 & $\$ 37,557$ & $\$ 11,304$ & $\$ 48,861$ & $\$ 398,544$ \\
\hline 77 & 72 & $\$ 37,557$ & $\$ 11,304$ & $\$ 48,861$ & $\$ 447,405$ \\
\hline 78 & 73 & $\$ 37,557$ & $\$ 11,304$ & $\$ 48,861$ & $\$ 496,266$ \\
\hline 79 & 74 & $\$ 37,557$ & $\$ 11,304$ & $\$ 48,861$ & $\$ 545,126$ \\
\hline 80 & 75 & $\$ 37,557$ & $\$ 11,304$ & $\$ 48,861$ & $\$ 593,987$ \\
\hline 81 & 76 & $\$ 37,557$ & $\$ 11,304$ & $\$ 48,861$ & $\$ 642,848$ \\
\hline 82 & 77 & $\$ 37,557$ & $\$ 11,304$ & $\$ 48,861$ & $\$ 691,708$ \\
\hline 83 & 78 & $\$ 37,557$ & $\$ 11,304$ & $\$ 48,861$ & $\$ 740,569$ \\
\hline 84 & 79 & $\$ 37,557$ & $\$ 11,304$ & $\$ 48,861$ & $\$ 789,430$ \\
\hline 85 & 80 & $\$ 37,557$ & $\$ 11,304$ & $\$ 48,861$ & $\$ 838,290$ \\
\hline 86 & 81 & $\$ 37,557$ & $\$ 11,304$ & $\$ 48,861$ & $\$ 887,151$ \\
\hline 87 & 82 & $\$ 37,557$ & $\$ 11,304$ & $\$ 48,861$ & $\$ 936,012$ \\
\hline 88 & 83 & $\$ 37,557$ & $\$ 11,304$ & $\$ 48,861$ & $\$ 984,872$ \\
\hline 89 & 84 & $\$ 37,557$ & $\$ 11,304$ & $\$ 48,861$ & $\$ 1,033,733$ \\
\hline 90 & 85 & $\$ 37,557$ & $\$ 11,304$ & $\$ 48,861$ & $\$ 1,082,593$ \\
\hline 91 & 86 & $\$ 0$ & $\$ 37,557$ & $\$ 37,557$ & $\$ 1,120,150$ \\
\hline 92 & 87 & $\$ 0$ & $\$ 37,557$ & $\$ 37,557$ & $\$ 1,157,707$ \\
\hline 93 & 88 & $\$ 0$ & $\$ 37,557$ & $\$ 37,557$ & $\$ 1,195,263$ \\
\hline 94 & 89 & $\$ 0$ & $\$ 37,557$ & $\$ 37,557$ & $\$ 1,232,820$ \\
\hline 95 & 90 & $\$ 0$ & $\$ 37,557$ & $\$ 37,557$ & $\$ 1,270,377$ \\
\hline
\end{tabular}

Table assumes PIA of $\$ 2,371$ (A) and PIA of $\$ 1,478(\mathrm{~B})$. DRC $=1.32$. WEP $(\mathrm{B})=\$ 222$. "B" starts at 62 which reduces benefits to 0.75 of PIA(B). - Age of death is 90 (spouse A) and 90 (spouse B).

\section{ANALYSIS OF CALCULATED TABLES FOR STRATEGY 2}

Strategy 2 evaluates whether a couple meeting our assumptions of age differences and PIA ratio should delay taking social security benefits. For strategy 2, spouse "A" does not take benefits until 70 years of age. Spouse "B" waits until 65 to begin benefits. Spouse "A" has annual benefits at 70 of $\$ 37,557$ (=12 X $1.32 \times 2371)$. Spouse "B" has annual benefits of $\$ 14,067$ (=12 X 0.9333 X 1256). The factor 0.9333 reflects "B"s retirement benefit reduction because " $\mathrm{B}$ " is 65 , or one year less than full retirement age.

Looking at Table 6, Strategy 2 for $75 / 90$, spouse "A" does not take benefits until 70 years of age. Spouse "B" waits until 65 to begin benefits. Spouse "A" has annual benefits at 70 of $\$ 37,557$ (=12 X 1.32 X 2371). Spouse "B" has annual benefits of $\$ 14,067(=12$ X 0.9333 X 1256). The factor 0.9333 reflects "B"s retirement benefit reduction because " $\mathrm{B}$ " is 65 , or one year less than full retirement age. The combined benefit for the couple is $\$ 51,623$. The higher total benefit continues until " $A$ " dies and spouse " $B$ " begins receiving survivor benefits of $\$ 37,557$ at 71 years of age. The annual benefit of $\$ 37,557$ continues until "B" dies after 90 years. The cumulative benefits for the couple are $\$ 309,740$ at the end of age 75 for spouse " $A$ " and are $\$ 1,060,873$ for the couple at the end of age 90 for spouse "B". 
Table 6 - Strategy 2 75/90 - Delay Start Of Benefits

Highest PIA Spouse Starts Benefits at 70; Other Spouse Begins Benefits at 65

\begin{tabular}{|c|c|c|c|c|c|}
\hline \multicolumn{2}{|c|}{ Age } & \multicolumn{4}{|c|}{ Benefits } \\
\hline Spouse A & Spouse B & Annual A & Annual B & Total & Cumulative \\
\hline 66 & 61 & & & & \\
\hline 67 & 62 & $\$ 0$ & $\$ 0$ & $\$ 0$ & $\$ 0$ \\
\hline 68 & 63 & $\$ 0$ & $\$ 0$ & $\$ 0$ & $\$ 0$ \\
\hline 69 & 64 & $\$ 0$ & $\$ 0$ & $\$ 0$ & $\$ 0$ \\
\hline 70 & 65 & $\$ 37,557$ & $\$ 14,067$ & $\$ 51,623$ & $\$ 51,623$ \\
\hline 71 & 66 & $\$ 37,557$ & $\$ 14,067$ & $\$ 51,623$ & $\$ 103,247$ \\
\hline 72 & 67 & $\$ 37,557$ & $\$ 14,067$ & $\$ 51,623$ & $\$ 154,870$ \\
\hline 73 & 68 & $\$ 37,557$ & $\$ 14,067$ & $\$ 51,623$ & $\$ 206,493$ \\
\hline 74 & 69 & $\$ 37,557$ & $\$ 14,067$ & $\$ 51,623$ & $\$ 258,117$ \\
\hline 75 & 70 & $\$ 37,557$ & $\$ 14,067$ & $\$ 51,623$ & $\$ 309,740$ \\
\hline 76 & 71 & $\$ 0$ & $\$ 37,557$ & $\$ 37,557$ & $\$ 347,297$ \\
\hline 77 & 72 & $\$ 0$ & $\$ 37,557$ & $\$ 37,557$ & $\$ 384,853$ \\
\hline 78 & 73 & $\$ 0$ & $\$ 37,557$ & $\$ 37,557$ & $\$ 422,410$ \\
\hline 79 & 74 & $\$ 0$ & $\$ 37,557$ & $\$ 37,557$ & $\$ 459,967$ \\
\hline 80 & 75 & $\$ 0$ & $\$ 37,557$ & $\$ 37,557$ & $\$ 497,523$ \\
\hline 81 & 76 & $\$ 0$ & $\$ 37,557$ & $\$ 37,557$ & $\$ 535,080$ \\
\hline 82 & 77 & $\$ 0$ & $\$ 37,557$ & $\$ 37,557$ & $\$ 572,637$ \\
\hline 83 & 78 & $\$ 0$ & $\$ 37,557$ & $\$ 37,557$ & $\$ 610,193$ \\
\hline 84 & 79 & $\$ 0$ & $\$ 37,557$ & $\$ 37,557$ & $\$ 647,750$ \\
\hline 85 & 80 & $\$ 0$ & $\$ 37,557$ & $\$ 37,557$ & $\$ 685,306$ \\
\hline 86 & 81 & $\$ 0$ & $\$ 37,557$ & $\$ 37,557$ & $\$ 722,863$ \\
\hline 87 & 82 & $\$ 0$ & $\$ 37,557$ & $\$ 37,557$ & $\$ 760,420$ \\
\hline 88 & 83 & $\$ 0$ & $\$ 37,557$ & $\$ 37,557$ & $\$ 797,976$ \\
\hline 89 & 84 & $\$ 0$ & $\$ 37,557$ & $\$ 37,557$ & $\$ 835,533$ \\
\hline 90 & 85 & $\$ 0$ & $\$ 37,557$ & $\$ 37,557$ & $\$ 873,090$ \\
\hline 91 & 86 & $\$ 0$ & $\$ 37,557$ & $\$ 37,557$ & $\$ 910,646$ \\
\hline 92 & 87 & $\$ 0$ & $\$ 37,557$ & $\$ 37,557$ & $\$ 948,203$ \\
\hline 93 & 88 & $\$ 0$ & $\$ 37,557$ & $\$ 37,557$ & $\$ 985,760$ \\
\hline 94 & 89 & $\$ 0$ & $\$ 37,557$ & $\$ 37,557$ & $\$ 1,023,316$ \\
\hline 95 & 90 & $\$ 0$ & $\$ 37,557$ & $\$ 37,557$ & $\$ 1,060,873$ \\
\hline
\end{tabular}

Table assumes PIA of $\$ 2,371$ (A) and PIA of $\$ 1,478(\mathrm{~B})$. DRC $=1.32$. WEP (B) $=\$ 222$. "B" starts at 65 which reduces benefits to 0.9333 of PIA(B). Age of death is 75 (spouse A) and 90 (spouse B).

Tables 7, 8, and 9 illustrate strategy 2 for spousal ages of 80/90, 85/90 and 90/90. As in Table 6, spouse "A" does not take benefits until 70 years of age. Spouse "B" waits until 65 to begin benefits. Spouse "A" has annual benefits at 70 of $\$ 37,557$ (= 12 X $1.32 \times 2371)$. Spouse "B" has annual benefits of $\$ 14,067$ (= 12 X 0.9333 $X$ 1256). The combined benefit for the couple is $\$ 51,623$. The higher total benefit continues until " $A$ " dies and spouse "B" begins receiving survivor benefits of $\$ 37,557$ at 81 years of age. The annual benefit of $\$ 37,557$ continues until "B" dies after 90 years.

Table 7 - Strategy 2 - 80/90 - Delay Start Of Benefits

Highest PIA Spouse Starts Benefits at 70; Other Spouse Begins Benefits at 65

\begin{tabular}{|c|c|c|c|c|c|}
\hline \multicolumn{2}{|c|}{ Age } & \multicolumn{4}{|c|}{ Benefits } \\
\hline Spouse A & Spouse B & Annual A & Annual B & Total & Cumulative \\
\hline 66 & 61 & & & & \\
\hline 67 & 62 & $\$ 0$ & $\$ 0$ & $\$ 0$ & $\$ 0$ \\
\hline 68 & 63 & $\$ 0$ & $\$ 0$ & $\$ 0$ & $\$ 0$ \\
\hline 69 & 64 & $\$ 0$ & $\$ 0$ & $\$ 0$ & $\$ 0$ \\
\hline 70 & 65 & $\$ 37,557$ & $\$ 14,067$ & $\$ 51,623$ & $\$ 51,623$ \\
\hline 71 & 66 & $\$ 37,557$ & $\$ 14,067$ & $\$ 51,623$ & $\$ 103,247$ \\
\hline 72 & 67 & $\$ 37,557$ & $\$ 14,067$ & $\$ 51,623$ & $\$ 154,870$ \\
\hline 73 & 68 & $\$ 37,557$ & $\$ 14,067$ & $\$ 51,623$ & $\$ 206,493$ \\
\hline 74 & 69 & $\$ 37,557$ & $\$ 14,067$ & $\$ 51,623$ & $\$ 258,117$ \\
\hline 75 & 70 & $\$ 37,557$ & $\$ 14,067$ & $\$ 51,623$ & $\$ 309,740$ \\
\hline 76 & 71 & $\$ 37,557$ & $\$ 14,067$ & $\$ 51,623$ & $\$ 361,363$ \\
\hline 77 & 72 & $\$ 37,557$ & $\$ 14,067$ & $\$ 51,623$ & $\$ 412,987$ \\
\hline 78 & 73 & $\$ 37,557$ & $\$ 14,067$ & $\$ 51,623$ & $\$ 464,610$ \\
\hline 79 & 74 & $\$ 37,557$ & $\$ 14,067$ & $\$ 51,623$ & $\$ 516,233$ \\
\hline 80 & 75 & $\$ 37,557$ & $\$ 14,067$ & $\$ 51,623$ & $\$ 567,857$ \\
\hline
\end{tabular}




\begin{tabular}{|c|c|c|c|c|c|}
\hline 81 & 76 & $\$ 0$ & $\$ 37,557$ & $\$ 37,557$ & $\$ 605,413$ \\
\hline 82 & 77 & $\$ 0$ & $\$ 37,557$ & $\$ 37,557$ & $\$ 642,970$ \\
\hline 83 & 78 & $\$ 0$ & $\$ 37,557$ & $\$ 37,557$ & $\$ 680,527$ \\
\hline 84 & 79 & $\$ 0$ & $\$ 37,557$ & $\$ 37,557$ & $\$ 718,083$ \\
\hline 85 & 80 & $\$ 0$ & $\$ 37,557$ & $\$ 37,557$ & $\$ 755,640$ \\
\hline 86 & 81 & $\$ 0$ & $\$ 37,557$ & $\$ 37,557$ & $\$ 793,197$ \\
\hline 87 & 82 & $\$ 0$ & $\$ 37,557$ & $\$ 37,557$ & $\$ 830,753$ \\
\hline 88 & 83 & $\$ 0$ & $\$ 37,557$ & $\$ 37,557$ & $\$ 868,310$ \\
\hline 89 & 84 & $\$ 0$ & $\$ 37,557$ & $\$ 37,557$ & $\$ 905,866$ \\
\hline 90 & 85 & $\$ 0$ & $\$ 37,557$ & $\$ 37,557$ & $\$ 943,423$ \\
\hline 91 & 86 & $\$ 0$ & $\$ 37,557$ & $\$ 37,557$ & $\$ 980,980$ \\
\hline 92 & 87 & $\$ 0$ & $\$ 37,557$ & $\$ 37,557$ & $\$ 1,018,536$ \\
\hline 93 & 88 & $\$ 0$ & $\$ 37,557$ & $\$ 37,557$ & $\$ 1,056,093$ \\
\hline 94 & 89 & $\$ 0$ & $\$ 37,557$ & $\$ 37,557$ & $\$ 1,093,650$ \\
\hline 95 & 90 & $\$ 0$ & $\$ 37,557$ & $\$ 37,557$ & $\$ 1,131,206$ \\
\hline
\end{tabular}

Table assumes PIA of $\$ 2,371$ (A) and PIA of $\$ 1,478(\mathrm{~B})$. DRC $=1.32$. WEP $(\mathrm{B})=\$ 222$. "B" starts at 65 which reduces benefits to 0.9333 of PIA(B). Age of death is 80 (spouse A) and 90 (spouse B).

The cumulative benefits for the couple who survives to $80 / 90$ (Table 7) are $\$ 567,857$ at the end of age 80 for spouse "A" and are $\$ 1,131,206$ for the couple at the end of age 90 for spouse "B". Similarly, the cumulative benefits for the couple who survives to $85 / 90$ (Table 8) are $\$ 825,973$ at the end of age 85 for spouse "A" and are $\$ 1,201,540$ for the couple at the end of age 90 for spouse "B". The cumulative benefits for the couple who survives to $90 / 90$ (Table 9) are $\$ 1,084,090$ at the end of age 90 for spouse " $A$ " and are $\$ 1,271,873$ for the couple at the end of age 90 for spouse "B".

Table 8 - Strategy 2 - 85/90 - Delay Start Of Benefits

Highest PIA Spouse Starts Benefits at 70; Other Spouse Begins Benefits at 65

\begin{tabular}{|c|c|c|c|c|c|}
\hline \multicolumn{2}{|c|}{ Age } & \multicolumn{4}{|c|}{ Benefits } \\
\hline Spouse A & Spouse B & Annual A & Annual B & Total & Cumulative \\
\hline 66 & 61 & & & & \\
\hline 67 & 62 & $\$ 0$ & $\$ 0$ & $\$ 0$ & $\$ 0$ \\
\hline 68 & 63 & $\$ 0$ & $\$ 0$ & $\$ 0$ & $\$ 0$ \\
\hline 69 & 64 & $\$ 0$ & $\$ 0$ & $\$ 0$ & $\$ 0$ \\
\hline 70 & 65 & $\$ 37,557$ & $\$ 14,067$ & $\$ 51,623$ & $\$ 51,623$ \\
\hline 71 & 66 & $\$ 37,557$ & $\$ 14,067$ & $\$ 51,623$ & $\$ 103,247$ \\
\hline 72 & 67 & $\$ 37,557$ & $\$ 14,067$ & $\$ 51,623$ & $\$ 154,870$ \\
\hline 73 & 68 & $\$ 37,557$ & $\$ 14,067$ & $\$ 51,623$ & $\$ 206,493$ \\
\hline 74 & 69 & $\$ 37,557$ & $\$ 14,067$ & $\$ 51,623$ & $\$ 258,117$ \\
\hline 75 & 70 & $\$ 37,557$ & $\$ 14,067$ & $\$ 51,623$ & $\$ 309,740$ \\
\hline 76 & 71 & $\$ 37,557$ & $\$ 14,067$ & $\$ 51,623$ & $\$ 361,363$ \\
\hline 77 & 72 & $\$ 37,557$ & $\$ 14,067$ & $\$ 51,623$ & $\$ 412,987$ \\
\hline 78 & 73 & $\$ 37,557$ & $\$ 14,067$ & $\$ 51,623$ & $\$ 464,610$ \\
\hline 79 & 74 & $\$ 37,557$ & $\$ 14,067$ & $\$ 51,623$ & $\$ 516,233$ \\
\hline 80 & 75 & $\$ 37,557$ & $\$ 14,067$ & $\$ 51,623$ & $\$ 567,857$ \\
\hline 81 & 76 & $\$ 37,557$ & $\$ 14,067$ & $\$ 51,623$ & $\$ 619,480$ \\
\hline 82 & 77 & $\$ 37,557$ & $\$ 14,067$ & $\$ 51,623$ & $\$ 671,103$ \\
\hline 83 & 78 & $\$ 37,557$ & $\$ 14,067$ & $\$ 51,623$ & $\$ 722,727$ \\
\hline 84 & 79 & $\$ 37,557$ & $\$ 14,067$ & $\$ 51,623$ & $\$ 774,350$ \\
\hline 85 & 80 & $\$ 37,557$ & $\$ 14,067$ & $\$ 51,623$ & $\$ 825,973$ \\
\hline 86 & 81 & $\$ 0$ & $\$ 37,557$ & $\$ 37,557$ & $\$ 863,530$ \\
\hline 87 & 82 & $\$ 0$ & $\$ 37,557$ & $\$ 37,557$ & $\$ 901,087$ \\
\hline 88 & 83 & $\$ 0$ & $\$ 37,557$ & $\$ 37,557$ & $\$ 938,643$ \\
\hline 89 & 84 & $\$ 0$ & $\$ 37,557$ & $\$ 37,557$ & $\$ 976,200$ \\
\hline 90 & 85 & $\$ 0$ & $\$ 37,557$ & $\$ 37,557$ & $\$ 1,013,757$ \\
\hline 91 & 86 & $\$ 0$ & $\$ 37,557$ & $\$ 37,557$ & $\$ 1,051,313$ \\
\hline 92 & 87 & $\$ 0$ & $\$ 37,557$ & $\$ 37,557$ & $\$ 1,088,870$ \\
\hline 93 & 88 & $\$ 0$ & $\$ 37,557$ & $\$ 37,557$ & $\$ 1,126,427$ \\
\hline 94 & 89 & $\$ 0$ & $\$ 37,557$ & $\$ 37,557$ & $\$ 1,163,983$ \\
\hline 95 & 90 & $\$ 0$ & $\$ 37,557$ & $\$ 37,557$ & $\$ 1,201,540$ \\
\hline
\end{tabular}

Table assumes PIA of $\$ 2,371(\mathrm{~A})$ and PIA of $\$ 1,478(\mathrm{~B})$. DRC $=1.32$. WEP (B) $=\$ 222$. "B" starts at 65 which reduces benefits to 0.9333 of PIA(B). Age of death is 85 (spouse A) and 90 (spouse B). 
Table 9 - Strategy 2 - 90/90 - Delay Start Of Benefits

Highest PIA Spouse Starts Benefits at 70; Other Spouse Begins Benefits at 65

\begin{tabular}{|c|c|c|c|c|c|}
\hline \multicolumn{2}{|c|}{ Age } & \multicolumn{4}{|c|}{ Benefits } \\
\hline Spouse A & Spouse B & Annual A & Annual B & Total & Cumulative \\
\hline 66 & 61 & & & & \\
\hline 67 & 62 & $\$ 0$ & $\$ 0$ & $\$ 0$ & $\$ 0$ \\
\hline 68 & 63 & $\$ 0$ & $\$ 0$ & $\$ 0$ & $\$ 0$ \\
\hline 69 & 64 & $\$ 0$ & $\$ 0$ & $\$ 0$ & $\$ 0$ \\
\hline 70 & 65 & $\$ 37,557$ & $\$ 14,067$ & $\$ 51,623$ & $\$ 51,623$ \\
\hline 71 & 66 & $\$ 37,557$ & $\$ 14,067$ & $\$ 51,623$ & $\$ 103,247$ \\
\hline 72 & 67 & $\$ 37,557$ & $\$ 14,067$ & $\$ 51,623$ & $\$ 154,870$ \\
\hline 73 & 68 & $\$ 37,557$ & $\$ 14,067$ & $\$ 51,623$ & $\$ 206,493$ \\
\hline 74 & 69 & $\$ 37,557$ & $\$ 14,067$ & $\$ 51,623$ & $\$ 258,117$ \\
\hline 75 & 70 & $\$ 37,557$ & $\$ 14,067$ & $\$ 51,623$ & $\$ 309,740$ \\
\hline 76 & 71 & $\$ 37,557$ & $\$ 14,067$ & $\$ 51,623$ & $\$ 361,363$ \\
\hline 77 & 72 & $\$ 37,557$ & $\$ 14,067$ & $\$ 51,623$ & $\$ 412,987$ \\
\hline 78 & 73 & $\$ 37,557$ & $\$ 14,067$ & $\$ 51,623$ & $\$ 464,610$ \\
\hline 79 & 74 & $\$ 37,557$ & $\$ 14,067$ & $\$ 51,623$ & $\$ 516,233$ \\
\hline 80 & 75 & $\$ 37,557$ & $\$ 14,067$ & $\$ 51,623$ & $\$ 567,857$ \\
\hline 81 & 76 & $\$ 37,557$ & $\$ 14,067$ & $\$ 51,623$ & $\$ 619,480$ \\
\hline 82 & 77 & $\$ 37,557$ & $\$ 14,067$ & $\$ 51,623$ & $\$ 671,103$ \\
\hline 83 & 78 & $\$ 37,557$ & $\$ 14,067$ & $\$ 51,623$ & $\$ 722,727$ \\
\hline 84 & 79 & $\$ 37,557$ & $\$ 14,067$ & $\$ 51,623$ & $\$ 774,350$ \\
\hline 85 & 80 & $\$ 37,557$ & $\$ 14,067$ & $\$ 51,623$ & $\$ 825,973$ \\
\hline 86 & 81 & $\$ 37,557$ & $\$ 14,067$ & $\$ 51,623$ & $\$ 877,597$ \\
\hline 87 & 82 & $\$ 37,557$ & $\$ 14,067$ & $\$ 51,623$ & $\$ 929,220$ \\
\hline 88 & 83 & $\$ 37,557$ & $\$ 14,067$ & $\$ 51,623$ & $\$ 980,843$ \\
\hline 89 & 84 & $\$ 37,557$ & $\$ 14,067$ & $\$ 51,623$ & $\$ 1,032,467$ \\
\hline 90 & 85 & $\$ 37,557$ & $\$ 14,067$ & $\$ 51,623$ & $\$ 1,084,090$ \\
\hline 91 & 86 & $\$ 0$ & $\$ 37,557$ & $\$ 37,557$ & $\$ 1,121,647$ \\
\hline 92 & 87 & $\$ 0$ & $\$ 37,557$ & $\$ 37,557$ & $\$ 1,159,203$ \\
\hline 93 & 88 & $\$ 0$ & $\$ 37,557$ & $\$ 37,557$ & $\$ 1,196,760$ \\
\hline 94 & 89 & $\$ 0$ & $\$ 37,557$ & $\$ 37,557$ & $\$ 1,234,317$ \\
\hline 95 & 90 & $\$ 0$ & $\$ 37,557$ & $\$ 37,557$ & $\$ 1,271,873$ \\
\hline
\end{tabular}

Table assumes PIA of $\$ 2,371(\mathrm{~A})$ and PIA of $\$ 1,478(\mathrm{~B})$. DRC $=1.32$. WEP (B) $=\$ 222$. "B" starts at 65 which reduces benefits to 0.9333 of PIA(B). Age of death is 90 (spouse A) and 90 (spouse B).

\section{ANALYSIS OF CALCULATED TABLES FOR STRATEGY 3}

Strategy 3 evaluates whether a couple meeting our assumptions of age differences and PIA ratio should begin social security benefits as soon as the younger spouse is eligible. For strategy 3, spouse "A" begins their retirement benefits when the younger spouse "B" can begin taking their retirement benefits. Spouse "A" has annual benefits of $\$ 30,728$ (= $12 \times 1.08 \times 2371)$. The factor 1.08 reflects the DRC gained by delaying beginning benefits by one year. The annual benefits for "B" are $\$ 11,304(=12$ X (1478-222) X 0.75).

Looking at Table 10, Strategy 3 for 75/90, spouse "A" begins their retirement benefits when the younger spouse "B" can first begin taking their retirement benefits. Spouse "A" has annual benefits of $\$ 30,728(=12$ X 1.08 $\mathrm{X} 2371$ ). The factor 1.08 reflects the DRC gained by delaying beginning benefits by one year. The annual benefits for "B" are $\$ 11,304(=12 \times(1478-222) \times 0.75)$. The total annual benefit for the couple is $\$ 42,032$. The higher total benefit continues until "A" dies and spouse "B" begins receiving survivor benefits of $\$ 30,728$ at 71 years of age. The annual benefits of $\$ 30,728$ continue until " $\mathrm{B}$ " dies after 90 years. The cumulative benefits for the couple are $\$ 378,289$ at the end of age 75 for spouse "A" and are $\$ 992,853$ for the couple at the end of age 90 for spouse "B". 
Table 10 - Strategy 3 - 75/90 - Early Start Of Benefits

Begin Social Security Benefits When Youngest Partner Become Eligible On Their Record

\begin{tabular}{|c|c|c|c|c|c|}
\hline \multicolumn{2}{|c|}{ Age } & \multicolumn{4}{|c|}{ Benefits } \\
\hline Spouse A & Spouse B & Annual A & Annual B & Total & Cumulative \\
\hline 66 & 61 & & & & \\
\hline 67 & 62 & $\$ 30,728$ & $\$ 11,304$ & $\$ 42,032$ & $\$ 42,032$ \\
\hline 68 & 63 & $\$ 30,728$ & $\$ 11,304$ & $\$ 42,032$ & $\$ 84,064$ \\
\hline 69 & 64 & $\$ 30,728$ & $\$ 11,304$ & $\$ 42,032$ & $\$ 126,096$ \\
\hline 70 & 65 & $\$ 30,728$ & $\$ 11,304$ & $\$ 42,032$ & $\$ 168,129$ \\
\hline 71 & 66 & $\$ 30,728$ & $\$ 11,304$ & $\$ 42,032$ & $\$ 210,161$ \\
\hline 72 & 67 & $\$ 30,728$ & $\$ 11,304$ & $\$ 42,032$ & $\$ 252,193$ \\
\hline 73 & 68 & $\$ 30,728$ & $\$ 11,304$ & $\$ 42,032$ & $\$ 294,225$ \\
\hline 74 & 69 & $\$ 30,728$ & $\$ 11,304$ & $\$ 42,032$ & $\$ 336,257$ \\
\hline 75 & 70 & $\$ 30,728$ & $\$ 11,304$ & $\$ 42,032$ & $\$ 378,289$ \\
\hline 76 & 71 & $\$ 0$ & $\$ 30,728$ & $\$ 30,728$ & $\$ 409,018$ \\
\hline 77 & 72 & $\$ 0$ & $\$ 30,728$ & $\$ 30,728$ & $\$ 439,746$ \\
\hline 78 & 73 & $\$ 0$ & $\$ 30,728$ & $\$ 30,728$ & $\$ 470,474$ \\
\hline 79 & 74 & $\$ 0$ & $\$ 30,728$ & $\$ 30,728$ & $\$ 501,202$ \\
\hline 80 & 75 & $\$ 0$ & $\$ 30,728$ & $\$ 30,728$ & $\$ 531,930$ \\
\hline 81 & 76 & $\$ 0$ & $\$ 30,728$ & $\$ 30,728$ & $\$ 562,658$ \\
\hline 82 & 77 & $\$ 0$ & $\$ 30,728$ & $\$ 30,728$ & $\$ 593,387$ \\
\hline 83 & 78 & $\$ 0$ & $\$ 30,728$ & $\$ 30,728$ & $\$ 624,115$ \\
\hline 84 & 79 & $\$ 0$ & $\$ 30,728$ & $\$ 30,728$ & $\$ 654,843$ \\
\hline 85 & 80 & $\$ 0$ & $\$ 30,728$ & $\$ 30,728$ & $\$ 685,571$ \\
\hline 86 & 81 & $\$ 0$ & $\$ 30,728$ & $\$ 30,728$ & $\$ 716,299$ \\
\hline 87 & 82 & $\$ 0$ & $\$ 30,728$ & $\$ 30,728$ & $\$ 747,027$ \\
\hline 88 & 83 & $\$ 0$ & $\$ 30,728$ & $\$ 30,728$ & $\$ 777,756$ \\
\hline 89 & 84 & $\$ 0$ & $\$ 30,728$ & $\$ 30,728$ & $\$ 808,484$ \\
\hline 90 & 85 & $\$ 0$ & $\$ 30,728$ & $\$ 30,728$ & $\$ 839,212$ \\
\hline 91 & 86 & $\$ 0$ & $\$ 30,728$ & $\$ 30,728$ & $\$ 869,940$ \\
\hline 92 & 87 & $\$ 0$ & $\$ 30,728$ & $\$ 30,728$ & $\$ 900,668$ \\
\hline 93 & 88 & $\$ 0$ & $\$ 30,728$ & $\$ 30,728$ & $\$ 931,396$ \\
\hline 94 & 89 & $\$ 0$ & $\$ 30,728$ & $\$ 30,728$ & $\$ 962,124$ \\
\hline 95 & 90 & $\$ 0$ & $\$ 30,728$ & $\$ 30,728$ & $\$ 992,853$ \\
\hline
\end{tabular}

Table assumes PIA of $\$ 2,371(\mathrm{~A})$ and PIA of $\$ 1,478(\mathrm{~B})$. DRC $=1.08$. WEP $(\mathrm{B})=\$ 222$. "B" starts at 62 which reduces benefits to 0.75 of PIA(B). Age of death is 75 (spouse A) and 90 (spouse B).

Tables 11, 12 and 13 illustrate strategy 3 for 80/90, 85/90, and 90/90. As in Table 10, spouse "A" begins retirement benefits when the younger spouse "B" can first begin taking retirement benefits. Spouse "A" has annual benefits of $\$ 30,728$ (= 12 X 1.08 X 2371). The annual benefits for "B" are $\$ 11,304$ (=12 X (1478-222) X 0.75). The total annual benefit for the couple is $\$ 42,032$. The higher total benefit continues until "A" dies and spouse "B" begins receiving survivor benefits of $\$ 30,728$ at 76 years of age. The annual benefits of $\$ 30,728$ continue until " $\mathrm{B}$ " dies after 90 years.

The cumulative benefits for the couple who survive to $80 / 90$ (Table 11) are $\$ 588,450$ at the end of age 80 for spouse "A" and are $\$ 1,049,373$ for the couple at the end of age 90 for spouse "B". Similarly, the cumulative benefits for the couple who survives to $85 / 90$ (Table 12) are $\$ 798,611$ at the end of age 85 for spouse "A" and are $\$ 1,105,893$ for the couple at the end of age 90 for spouse "B". The cumulative benefits for the couple who survives to $90 / 90$ (Table 13) are $\$ 1,008,772$ at the end of age 90 for spouse "A" and are $\$ 1,162,413$ for the couple at the end of age 90 for spouse "B". 
Table 11 - Strategy 3 - 80/90 - Early Start Of Benefits

Begin Social Security Benefits When Youngest Partner Become Eligible On Their Record

\begin{tabular}{|c|c|c|c|c|c|}
\hline \multicolumn{2}{|c|}{ Age } & \multicolumn{4}{|c|}{ Benefits } \\
\hline Spouse A & Spouse B & Annual A & Annual B & Total & Cumulative \\
\hline 66 & 61 & & & & \\
\hline 67 & 62 & $\$ 30,728$ & $\$ 11,304$ & $\$ 42,032$ & $\$ 42,032$ \\
\hline 68 & 63 & $\$ 30,728$ & $\$ 11,304$ & $\$ 42,032$ & $\$ 84,064$ \\
\hline 69 & 64 & $\$ 30,728$ & $\$ 11,304$ & $\$ 42,032$ & $\$ 126,096$ \\
\hline 70 & 65 & $\$ 30,728$ & $\$ 11,304$ & $\$ 42,032$ & $\$ 168,129$ \\
\hline 71 & 66 & $\$ 30,728$ & $\$ 11,304$ & $\$ 42,032$ & $\$ 210,161$ \\
\hline 72 & 67 & $\$ 30,728$ & $\$ 11,304$ & $\$ 42,032$ & $\$ 252,193$ \\
\hline 73 & 68 & $\$ 30,728$ & $\$ 11,304$ & $\$ 42,032$ & $\$ 294,225$ \\
\hline 74 & 69 & $\$ 30,728$ & $\$ 11,304$ & $\$ 42,032$ & $\$ 336,257$ \\
\hline 75 & 70 & $\$ 30,728$ & $\$ 11,304$ & $\$ 42,032$ & $\$ 378,289$ \\
\hline 76 & 71 & $\$ 30,728$ & $\$ 11,304$ & $\$ 42,032$ & $\$ 420,322$ \\
\hline 77 & 72 & $\$ 30,728$ & $\$ 11,304$ & $\$ 42,032$ & $\$ 462,354$ \\
\hline 78 & 73 & $\$ 30,728$ & $\$ 11,304$ & $\$ 42,032$ & $\$ 504,386$ \\
\hline 79 & 74 & $\$ 30,728$ & $\$ 11,304$ & $\$ 42,032$ & $\$ 546,418$ \\
\hline 80 & 75 & $\$ 30,728$ & $\$ 11,304$ & $\$ 42,032$ & $\$ 588,450$ \\
\hline 81 & 76 & $\$ 0$ & $\$ 30,728$ & $\$ 30,728$ & $\$ 619,178$ \\
\hline 82 & 77 & $\$ 0$ & $\$ 30,728$ & $\$ 30,728$ & $\$ 649,907$ \\
\hline 83 & 78 & $\$ 0$ & $\$ 30,728$ & $\$ 30,728$ & $\$ 680,635$ \\
\hline 84 & 79 & $\$ 0$ & $\$ 30,728$ & $\$ 30,728$ & $\$ 711,363$ \\
\hline 85 & 80 & $\$ 0$ & $\$ 30,728$ & $\$ 30,728$ & $\$ 742,091$ \\
\hline 86 & 81 & $\$ 0$ & $\$ 30,728$ & $\$ 30,728$ & $\$ 772,819$ \\
\hline 87 & 82 & $\$ 0$ & $\$ 30,728$ & $\$ 30,728$ & $\$ 803,547$ \\
\hline 88 & 83 & $\$ 0$ & $\$ 30,728$ & $\$ 30,728$ & $\$ 834,276$ \\
\hline 89 & 84 & $\$ 0$ & $\$ 30,728$ & $\$ 30,728$ & $\$ 865,004$ \\
\hline 90 & 85 & $\$ 0$ & $\$ 30,728$ & $\$ 30,728$ & $\$ 895,732$ \\
\hline 91 & 86 & $\$ 0$ & $\$ 30,728$ & $\$ 30,728$ & $\$ 926,460$ \\
\hline 92 & 87 & $\$ 0$ & $\$ 30,728$ & $\$ 30,728$ & $\$ 957,188$ \\
\hline 93 & 88 & $\$ 0$ & $\$ 30,728$ & $\$ 30,728$ & $\$ 987,916$ \\
\hline 94 & 89 & $\$ 0$ & $\$ 30,728$ & $\$ 30,728$ & $\$ 1,018,644$ \\
\hline 95 & 90 & $\$ 0$ & $\$ 30,728$ & $\$ 30,728$ & $\$ 1,049,373$ \\
\hline
\end{tabular}

Table assumes PIA of $\$ 2,371(\mathrm{~A})$ and PIA of $\$ 1,478(\mathrm{~B})$. DRC $=1.08$. WEP (B) $=\$ 222$. "B" starts at 62 which reduces benefits to 0.75 of PIA(B). Age of death is 80 (spouse A) and 90 (spouse B).

Table 12 - Strategy 3 - 85/90 - Early Start Of Benefits

Begin Social Security Benefits When Youngest Partner Become Eligible On Their Record

\begin{tabular}{|c|c|c|c|c|c|}
\hline \multicolumn{2}{|c|}{ Age } & \multicolumn{4}{|c|}{ Benefits } \\
\hline Spouse A & Spouse B & Annual A & Annual B & Total & Cumulative \\
\hline 66 & 61 & & & & \\
\hline 67 & 62 & $\$ 30,728$ & $\$ 11,304$ & $\$ 42,032$ & $\$ 42,032$ \\
\hline 68 & 63 & $\$ 30,728$ & $\$ 11,304$ & $\$ 42,032$ & $\$ 84,064$ \\
\hline 69 & 64 & $\$ 30,728$ & $\$ 11,304$ & $\$ 42,032$ & $\$ 126,096$ \\
\hline 70 & 65 & $\$ 30,728$ & $\$ 11,304$ & $\$ 42,032$ & $\$ 168,129$ \\
\hline 71 & 66 & $\$ 30,728$ & $\$ 11,304$ & $\$ 42,032$ & $\$ 210,161$ \\
\hline 72 & 67 & $\$ 30,728$ & $\$ 11,304$ & $\$ 42,032$ & $\$ 252,193$ \\
\hline 73 & 68 & $\$ 30,728$ & $\$ 11,304$ & $\$ 42,032$ & $\$ 294,225$ \\
\hline 74 & 69 & $\$ 30,728$ & $\$ 11,304$ & $\$ 42,032$ & $\$ 336,257$ \\
\hline 75 & 70 & $\$ 30,728$ & $\$ 11,304$ & $\$ 42,032$ & $\$ 378,289$ \\
\hline 76 & 71 & $\$ 30,728$ & $\$ 11,304$ & $\$ 42,032$ & $\$ 420,322$ \\
\hline 77 & 72 & $\$ 30,728$ & $\$ 11,304$ & $\$ 42,032$ & $\$ 462,354$ \\
\hline 78 & 73 & $\$ 30,728$ & $\$ 11,304$ & $\$ 42,032$ & $\$ 504,386$ \\
\hline 79 & 74 & $\$ 30,728$ & $\$ 11,304$ & $\$ 42,032$ & $\$ 546,418$ \\
\hline 80 & 75 & $\$ 30,728$ & $\$ 11,304$ & $\$ 42,032$ & $\$ 588,450$ \\
\hline 81 & 76 & $\$ 30,728$ & $\$ 11,304$ & $\$ 42,032$ & $\$ 630,482$ \\
\hline 82 & 77 & $\$ 30,728$ & $\$ 11,304$ & $\$ 42,032$ & $\$ 672,515$ \\
\hline 83 & 78 & $\$ 30,728$ & $\$ 11,304$ & $\$ 42,032$ & $\$ 714,547$ \\
\hline 84 & 79 & $\$ 30,728$ & $\$ 11,304$ & $\$ 42,032$ & $\$ 756,579$ \\
\hline 85 & 80 & $\$ 30,728$ & $\$ 11,304$ & $\$ 42,032$ & $\$ 798,611$ \\
\hline 86 & 81 & $\$ 0$ & $\$ 30,728$ & $\$ 30,728$ & $\$ 829,339$ \\
\hline 87 & 82 & $\$ 0$ & $\$ 30,728$ & $\$ 30,728$ & $\$ 860,067$ \\
\hline 88 & 83 & $\$ 0$ & $\$ 30,728$ & $\$ 30,728$ & $\$ 890,796$ \\
\hline
\end{tabular}




\begin{tabular}{|c|c|c|c|c|c|}
\hline 89 & 84 & $\$ 0$ & $\$ 30,728$ & $\$ 30,728$ \\
\hline 90 & 85 & $\$ 0$ & $\$ 30,728$ & $\$ 30,728$ \\
\hline 91 & 86 & $\$ 0$ & $\$ 30,728$ & $\$ 30,728$ \\
\hline 92 & 87 & $\$ 0$ & $\$ 30,728$ & $\$ 324,252$ \\
\hline 94 & 88 & $\$ 0$ & $\$ 30,728$ & $\$ 30,728$ \\
\hline 95 & 89 & $\$ 0$ & $\$ 30,728$ & $\$ 1,013,708$ & $\$ 30,728$ \\
\hline
\end{tabular}

Table assumes PIA of $\$ 2,371(\mathrm{~A})$ and PIA of $\$ 1,478(\mathrm{~B})$. DRC $=1.08$. WEP $(\mathrm{B})=\$ 222$. "B" starts at 62 which reduces benefits to 0.75 of PIA(B). Age of death is 85 (spouse A) and 90 (spouse B).

Table 13 - Strategy 3 - 90/90 - Early Start Of Benefits Begin Social Security Benefits When Youngest Partner Become Eligible On Their Record

\begin{tabular}{|c|c|c|c|c|c|}
\hline \multicolumn{2}{|c|}{ Age } & \multicolumn{4}{|c|}{ Benefits } \\
\hline Spouse A & Spouse B & Annual A & Annual B & Total & Cumulative \\
\hline 66 & 61 & & & & \\
\hline 67 & 62 & $\$ 30,728$ & $\$ 11,304$ & $\$ 42,032$ & $\$ 42,032$ \\
\hline 68 & 63 & $\$ 30,728$ & $\$ 11,304$ & $\$ 42,032$ & $\$ 84,064$ \\
\hline 69 & 64 & $\$ 30,728$ & $\$ 11,304$ & $\$ 42,032$ & $\$ 126,096$ \\
\hline 70 & 65 & $\$ 30,728$ & $\$ 11,304$ & $\$ 42,032$ & $\$ 168,129$ \\
\hline 71 & 66 & $\$ 30,728$ & $\$ 11,304$ & $\$ 42,032$ & $\$ 210,161$ \\
\hline 73 & 68 & $\$ 30,728$ & $\$ 11,304$ & $\$ 42,032$ & $\$ 294,225$ \\
\hline 74 & 69 & $\$ 30,728$ & $\$ 11,304$ & $\$ 42,032$ & $\$ 336,257$ \\
\hline 75 & 70 & $\$ 30,728$ & $\$ 11,304$ & $\$ 42,032$ & $\$ 378,289$ \\
\hline 76 & 71 & $\$ 30,728$ & $\$ 11,304$ & $\$ 42,032$ & $\$ 420,322$ \\
\hline 77 & 72 & $\$ 30,728$ & $\$ 11,304$ & $\$ 42,032$ & $\$ 462,354$ \\
\hline 78 & 73 & $\$ 30,728$ & $\$ 11,304$ & $\$ 42,032$ & $\$ 504,386$ \\
\hline 79 & 74 & $\$ 30,728$ & $\$ 11,304$ & $\$ 42,032$ & $\$ 546,418$ \\
\hline 81 & 76 & $\$ 30,728$ & $\$ 11,304$ & $\$ 42,032$ & $\$ 630,482$ \\
\hline 82 & 77 & $\$ 30,728$ & $\$ 11,304$ & $\$ 42,032$ & $\$ 672,515$ \\
\hline 83 & 78 & $\$ 30,728$ & $\$ 11,304$ & $\$ 42,032$ & $\$ 714,547$ \\
\hline 84 & 79 & $\$ 30,728$ & $\$ 11,304$ & $\$ 42,032$ & $\$ 756,579$ \\
\hline 85 & 80 & $\$ 30,728$ & $\$ 11,304$ & $\$ 42,032$ & $\$ 798,611$ \\
\hline 86 & 81 & $\$ 30,728$ & $\$ 11,304$ & $\$ 42,032$ & $\$ 840,643$ \\
\hline 87 & 82 & $\$ 30,728$ & $\$ 11,304$ & $\$ 42,032$ & $\$ 882,675$ \\
\hline 88 & 83 & $\$ 30,728$ & $\$ 11,304$ & $\$ 42,032$ & $\$ 924,708$ \\
\hline 89 & 84 & $\$ 30,728$ & $\$ 11,304$ & $\$ 42,032$ & $\$ 966,740$ \\
\hline 90 & 85 & $\$ 30,728$ & $\$ 11,304$ & $\$ 42,032$ & $\$ 1,008,772$ \\
\hline 91 & 86 & $\$ 0$ & $\$ 30,728$ & $\$ 30,728$ & $\$ 1,039,500$ \\
\hline 92 & 87 & $\$ 0$ & $\$ 30,728$ & $\$ 30,728$ & $\$ 1,070,228$ \\
\hline 93 & 88 & $\$ 0$ & $\$ 30,728$ & $\$ 30,728$ & $\$ 1,100,956$ \\
\hline 94 & 89 & $\$ 0$ & $\$ 30,728$ & $\$ 30,728$ & $\$ 1,131,684$ \\
\hline 95 & 90 & $\$ 0$ & $\$ 30,728$ & $\$ 30,728$ & $\$ 1,162,413$ \\
\hline
\end{tabular}

Table assumes PIA of $\$ 2,371(\mathrm{~A})$ and PIA of $\$ 1,478(\mathrm{~B})$. DRC $=1.08$. WEP $(\mathrm{B})=\$ 222$. "B" starts at 62 which reduces benefits to 0.75 of PIA(B). Age of death is 80 (spouse A) and 90 (spouse B).

\section{COMPARISON OF STRATEGIES}

A comparison of the three strategies is shown in Table 14, Comparison Of Strategies. The maximum benefits for each age at death of spouse A is in the cell with the heavy border. Based upon the maximum benefits received, strategy 3 , early start of benefits as soon as younger spouse is eligible, provides the most benefits through age of death at 75 . In strategy 3 , the total benefits received by the couple by age 75 of spouse A is $\$ 378,288$, which is more than either strategy 1 or 2 . Strategy 1 , however, provides the largest life time benefits assuming the surviving spouse lives to 90 .

For age of death at 80 , strategy 1, "restricted application" has the largest benefits for both spouses according to total individual benefits received by 80 for spouse A $(\$ 435,735)$, and for life time benefits received by the couple $(\$ 1,157,837)$. Note that for all death ages of spouse A $(75,80,85$, and 90$)$, the benefits received by spouse B during the relevant time period are equal for strategy 1 and strategy 3. Strategy 2 maximizes benefits to spouse B (\$225,072 and \$295,401 respectively) given an age at death of spouse A at 85 and 90. 
Except for age of death at 75, the benefits to spouse A are greatest for strategy 1 . For age of death at 75, strategy 3 (early start) provides the greatest benefits to spouse A. For couples, strategy 1 maximizes total life time benefits across all age of death categories except for the event of spouse "A" living to 90. If spouse A were to live to 90 , strategy 2 maximizes the life time benefits for couples $(\$ 1,271,878)$

Table 14

Comparison Of Strategies

\begin{tabular}{|c|c|c|c|c|c|}
\hline Strategy & $\begin{array}{c}\text { Age At Death } \\
\text { Of Spouse A }\end{array}$ & $\begin{array}{c}\text { Benefits Received } \\
\text { By A } \\
\end{array}$ & $\begin{array}{c}\text { Benefits } \\
\text { Received By B }\end{array}$ & $\begin{array}{c}\text { Total Benefits Received By } \\
\text { Couple During Life Of A }\end{array}$ & $\begin{array}{c}\text { Total Life Time Benefits } \\
\text { Received By Couple }\end{array}$ \\
\hline 1 & 75 & $\$ 249,950$ & $\$ 101,736$ & $\$ 349,686$ & $\$ 1,100,817$ \\
\hline 2 & 75 & $\$ 225,342$ & $\$ 84,402$ & $\$ 309,744$ & $\$ 1,060,873$ \\
\hline 3 & 75 & $\$ 276,552$ & $\$ 101,736$ & $\$ 378,288$ & $\$ 992,853$ \\
\hline 1 & 80 & $\$ 435,735$ & $\$ 158,256$ & $\$ 593,991$ & $\$ 1,157,837$ \\
\hline 2 & 80 & $\$ 413,127$ & $\$ 154,737$ & $\$ 567,864$ & $\$ 1,131,206$ \\
\hline 3 & 80 & $\$ 430,192$ & $\$ 158,256$ & $\$ 588,448$ & $\$ 1,049,373$ \\
\hline 1 & 85 & $\$ 623,520$ & $\$ 214,776$ & $\$ 838,296$ & $\$ 1,213,857$ \\
\hline 2 & 85 & $\$ 600,912$ & $\$ 225,072$ & $\$ 825,984$ & $\$ 1,201,540$ \\
\hline 3 & 85 & $\$ 583,832$ & $\$ 214,776$ & $\$ 798,608$ & $\$ 1,105,893$ \\
\hline 1 & 90 & $\$ 811,297$ & $\$ 271,296$ & $\$ 1,082,593$ & $\$ 1,270,377$ \\
\hline 2 & 90 & $\$ 788,689$ & $\$ 295,401$ & $\$ 1,084,090$ & $\$ 1,271,878$ \\
\hline 3 & 90 & $\$ 737,476$ & $\$ 271,296$ & $\$ 1,008,772$ & $\$ 1,162,413$ \\
\hline
\end{tabular}

In other words, the three strategies considered deliver optimal benefits at different ages based upon the age of death for spouse A. Strategy 3 (early start of benefits) would provide the largest benefits $(\$ 378,288)$ to the couple at age of death at 75 for A. Strategy 1 provides the largest benefits to the couple at the age of death of 80 and 85 for spouse A ( $\$ 593,991$ and $\$ 838,296$, respectively). Strategy 2 provides slightly larger benefits (about fifteen hundred dollars over the life time of the couple) if spouse A lives to 90 or beyond (\$1,084,090 for strategy 2 compared to $\$ 1,082,593$ for strategy 1$)$.

The overall results are summarized in Table 15, Optimal Strategy By Dollars By Age Of Death Of Spouse A. If you are spouse "A", and believe that you are likely to die before you reach your expected life span, strategy 3 provides the largest amount of benefits to you separately and to you and your spouse collectively at your age of death of 75 ( $\$ 276,552$ and $\$ 378,288$ respectively.) However, if spouse B would live to 90 , the life time benefits received by the couple are greater for strategy $1(\$ 1,100,817)$ compared to strategy $3(\$ 992,853)$. For spouse "A", age of death 80, strategy 1 provides the largest amount of benefits to you (spouse A) and to you and your spouse collectively ( $\$ 435,735$ and $\$ 1,157,837$ respectively.) For spouse "A", age of death 85 , strategy 1 provides the largest amount of benefits to you (spouse A) and to you and your spouse collectively $(\$ 623,520$ and $\$ 1,213,857$ respectively.)

If spouse "A" survives until 90, strategy 2 becomes more rewarding compared to strategy 1 based upon total benefits to the couple. The total benefits received by the couple during life of "A" are greater for strategy 2 compared to strategy 1 by $\$ 1497$ (= $\$ 1,084,090$ - $\$ 1,082,593$.) The total life time benefits received by the couple are greater for strategy 2 compared to strategy 1 by $\$ 1501(=\$ 1,271,878-\$ 1,270,377)$. However, for individual benefits to spouse " $\mathrm{A}$ " surviving to age 90 , strategy 1 continues to be the more rewarding at $\$ 811,297$.

Table 15

Optimal Strategy By Dollars By Age Of Death Of Spouse A

\begin{tabular}{|l|c|c|c|c|}
\hline Age of Death of Spouse A & 75 & 80 & 85 & 90 \\
\hline Strategy Which Maximizes Benefits to Spouse A During Life of Spouse A & 3 & 1 & 1 & 1 \\
\hline Maximum Benefit to Spouse A During Life of Spouse A & $\$ 276,552$ & $\$ 435,735$ & $\$ 623,520$ & $\$ 811,297$ \\
\hline Strategy Which Maximizes Total Life Time Benefits to Couple & 1 & 1 & 1 & 2 \\
\hline Maximum Total Life Time Benefits to Couple & $\$ 1,100,817$ & $\$ 1,157,837$ & $\$ 1,213,857$ & $\$ 1,271,878$ \\
\hline
\end{tabular}




\section{STRATEGY SELECTION, MORTALITY, AND LONGEVITY RISK}

Based upon comparison of the three strategies, which strategy is preferable (Spiegelman, 2011; Turner, 2010)? Although the dollar amounts likely to be received in benefits can be computed with various assumptions, what about life expectancy itself? Clearly, if a spouse has poor health and a low expected lifespan, would not an immediate start of benefits be the best strategy?

A review of the recent actuarial life tables (2007) provided by Social Security Administration (http://www.ssa.gov.oact/STATS/table4c6.html) offers some sobering assessments of long term strategies. At 67 years, a male has an expected life span of 15.77 years. Based upon the strategies presented in this paper, a life expectancy of 82.77 years suggests that strategy 1 would be preferable. About half of the men at 67 could expect to live to 82.77 years and collect the larger benefits computed for strategy 1 .

Another look at the actuarial life table illustrates the risk. The table notes that about 76,929 men out of every 100,000 born reach 67 years. (Yes, that's right, by 67 years of age, 23,071 men out of 100,000 are already deceased.) What is the likelihood of the 67 year old male surviving until 75? At 75 years of age, only 61,612 males remain-15,317 have passed on. About $19.9 \%$ of men living at 67 will die before or at 75 years. At 80 years of age, only 47,974 men remain-13,638 have passed. About $22.1 \%$ of men living at 75 will die before or at 80 years. According to the actuarial tables, only 47,974 men out of the 76,929 alive at 67 will survive to 80 -about $62.4 \%$.

Considering this cheery news, what about our strategies? Realistically, we are all mortal and likely to pass away unexpectedly. However, we know from actuarial tables that the probability of a 67 year old man living to 80 years is about $62.4 \%$ and the odds of living to 82.77 years are about 50-50. Strategy 1 provides the "best" return for the average couple considering male life expectancy.

However, there is another important consideration besides life expectancy: longevity risk (Reichenstein and Meyer, 2011). Reichenstein and Meyer define longevity risk as the risk that a couple will deplete their financial portfolio during their lifetime. In fact, many retirees express great fear of inflation or financial market disorder and a recent Allianz poll (2010) found that $61 \%$ of individuals would rather die than run out of money.

Comparing the total benefits accumulated across a life time for couples, strategy 1 provides the most cumulative benefits for couples at all ages of death for spouse "A" except 90. If spouse "A" lives to 90 years of age, strategy 2 gains about $\$ 1500$ more over the joint life span of the couple. Based upon cumulative benefits, strategy 1 and 2 would be the most likely to address longevity risk. However, given the greater benefits of strategy 1 for couples at all other ages of death for spouse "A", it would seem that strategy 1 provides the greatest benefits to spouse "A" and provides the largest benefits to couples given the alternative ages of death for spouse "A".

\section{SUMMARY AND RECOMMENDATIONS}

This paper presents analysis of three strategies to find which strategy provides optimal social security benefits to couples. It is assumed that the couples have a greater than average age difference of 5 years and that the couple has a ratio of PIA's of 0.5 or greater (lower PIA/higher PIA) based upon their individual work records. The focus on couples with these characteristics arises because of the sparse analysis provided in popular social security reference books and pamphlets. The age difference of 5 years or greater occurs in about one third of US marriages and the ratio of 0.5 is typical for baby boomer households in which both partners have worked throughout most of their lives. The above average age difference reduces the number of years in which joint strategy actions can be developed. The 5 year difference assumed in this analysis indicates that the older spouse will be a year past full retirement age by the year that the younger spouse becomes eligible for social security benefits.

As noted earlier, there are basically two strategies that are available to couples to jointly maximize social security benefits: "claim and suspend" and "restricted application". Both strategies require at least one spouse to be at FRA. The 0.5 ratio assumption precludes "claim and suspend" because the younger spouse can receive greater benefits on their own retirement benefits versus spousal benefits. Consequently, the only remaining joint strategy is "restricted application." In addition to the "restricted application, however, the spouses can still explore starting individual benefits early or late and evaluating the joint cumulative life benefits. 
The three strategies evaluated in this analysis are (1) Restricted application (2) Delayed Start--both spouses beginning benefits when the oldest spouse is 70, and (3) Early Start--both spouses beginning benefits when the youngest spouse is 62. As summarized in Table 14 and Table 15, strategy 1-“restricted application" -provides the largest comparative benefits for the life time benefits of the couple until 90 years age of death of spouse A. Also, the benefits received by spouse A during that individual's life time are greatest for strategy 1 except in the case of a life span below average life expectancy.

In regards to longevity risk, strategy 1 and strategy 2 provide the maximum DRC benefits for spouse A and the maximum survivor benefit for spouse B. There are two points to consider here. First, spouse A had the highest PIA and the survivor benefit is greatest with the DRC of $32 \%$ added to the highest PIA. Second, even if spouse B delayed their start of benefits until 70 years of age, the survivor benefit will begin with the death of spouse A. As earlier work has shown (Hebein, 2011), it takes about 12.5 years to "catch up" from a delayed start of benefits. (To make the impact of delayed start easier to understand, think of four years of forgone earnings at 1.0 per year. Starting benefits at $1.32-32 \%$ DRC-- in year 5 , requires 12.5 years $(=4.0 / .32)$ to recapture the forgone earnings.) Since spouse A is 5 years older, spouse A would already be at 87.5 years - 5 years past life expectancy-before spouse B would "break even" based on their decision to delay start of benefits. Therefore, it makes financial sense not to maximize spouse B benefits by delaying start of benefits past FRA to gain DRC.

Given the consideration of maximizing life time benefits and minimizing longevity risk by gaining a higher survivor benefit, strategy 1 is supported by the preceding analysis as the "best" choice of the three alternatives reviewed. Of course, if spouse A has a critical health issue that substantially reduces life span, strategy 3 would provide the highest benefits until the mid or late 70's in age of spouse A. However, if immediate cash requirements are not pressing, the surviving spouse receives the greatest benefits from strategy 1 even given an early age of death such as 75 for spouse A.

\section{AUTHOR INFORMATION}

Dr. Hebein has had a successful career in industry and academe. While serving as VP of Marketing and as Director of Business Development for several companies, he developed profitable marketing programs and directed product development programs to successful commercialization and patent acknowledgement. At California State University at San Bernardino, USA (CSUSB), where he is a tenured Professor, he has been awarded the title of Professor Emeritus. During his tenure with CSUSB, Dr. Hebein has received numerous awards for Teaching Excellence, Research and Publication, and Professional Service. Professor Hebein is also a charter member of the Teaching Academy, established for college professors with outstanding teaching evaluations. His current research interests are retirement planning and optimization of social security benefits. Dr. Hebein received his Ph. D. from Southern Methodist University and his Professional Degree in Engineering from the Colorado School of Mines. Contact Information: E-mail: fhebein@csusb.edu

\section{BIBLIOGRAPHY}

1. Blankenship, Jim. 2011. A Social Security Owner’s Manual. Jim@BlankenshipFinancial.com

2. Burtless, Gary. 1986. Social Security, Unanticipated Benefit Increases, and the Timing of Retirement. The Review of Economic Studies, vol. 53, no. 5, October, pp. 781-805.

3. $\quad$ Clements, Donna A. 2009. Guide to Social Security $\left(37^{\text {th }}\right.$ ed).

4. Crawford, Vincent P., and David M. Lilien. 1981. Social Security and the Retirement Decision. The Quarterly Journal of Economics, vol. 96, no. 3, August, pp. 505-529.

5. Duggar, James E., and Robert Gillingham. 1999. The Effect of Errors in the CPI on Social Security Finances. Journal of Business \&Economic Statistics, vol. 17, no. 2, April, pp. 161-169.

6. Fahlund, Christine. 2011. Delaying Retirement, But Not Your Retirement Dreams. American Association of Individual Investors, vol. 33, no. 7, July, pp. 13, 14, 17.

7. Fahlund, Christine. 2009. Retirement Income: Repairing the Damage to Assure the Flow. American Association of Individual Investors, vol. 31, no. 2, February, pp. 5-9.

8. Fisher, T. Lynn. 2007. Measuring the Relative Importance of Social Security Benefits to the Elderly. Social Security Bulletin, vol. 67, no. 2, pp. 65-72. 
9. Greenwald, Mathew., Kapteyn, Arie., Mitchell, Olivia., and Schneider, Lisa. 2010. What Do People Know About Social Security. Working Paper, WR-792-SSA, Rand Corporation, Prepared for the SSA by the Financial Literacy Center. October 2010.

10. Hebein, Fred. 2012. How Long Should An Individual At Full Retirement Age Delay Receiving Social Security Benefits? The Journal of Applied Business Research, vol. 28, no.3, pp. 1-14.

11. Henkens, Kène, and Hanna van Solinge. 2002. Spousal Influences on the Decision to Retire. International Journal of Sociology, vol. 32, no. 2, Summer, pp. 55-74.

12. Hobijn, Bart, and David Lagakos. 2003. Social Security and the Consumer Price Index for the Elderly. Federal Reserve Bank of New York, vol. 9, no. 5, May, pp. 1-6.

13. Hogan, Paula H. 2011. The Role of Inflation-Indexed Annuities. American Association of Individual Investors, vol. 33, no.3, March, pp. 29-32.

14. Johnson, Richard. 2002. The Puzzle of Later Male Retirement. Federal Reserve Bank of Kansas City Economic Review, Third Quarter, pp. 5-24.

15. Landis, Andy. 2012. Social Security The Inside Story.

16. Matthews, Joseph and Berman, Dorothy Matthews. 2012. Social Security, Medicare \& Government Pensions. (17 $7^{\text {th }}$ ed.) Nolo.

17. Muksian, Robert. 2011. Social Security: Delay or Take the Money and Run - Act II. American Association of Individual Investors, vol. 33, no. 5, May, pp. 13-16.

18. News Release. 2010. Outliving Your Money Feared More Than Death. Allianz Life Insurance Company of North America, June 17.

19. O'Rand, Angela M., and Janice, Parkas. 2002. Couples' Retirement Timing in the United States in the 1990s. International Journal of Sociology," vol. 32, no. 2, Summer, pp. 11, 19.

20. Reichenstein, William. 2008. Will Your Savings Last? What the Withdrawal Rate Studies Show. American Association of Individual Investors, vol. 30, no. 6, July, pp. 5-11.

21. Reichenstein, William and Meyer, William. 2011. Social Security Strategies.

22. Spiegelman, Rande. When Should You Take Social Security? Schwab Center for Financial Research, February 4, 2011, pp. 1-8.

23. Turner, John A. 2010. Rating Retirement Advice: A Critical Assessment of Retirement Planning Software. Benefits Quarterly, Fourth Quarter, pp. 40-49. 
NOTES 